\title{
B-Lymphocyte-Mediated Delayed Cognitive Impairment following Stroke
}

\author{
Kristian P. Doyle, ${ }^{1,2}$ Lisa N. Quach, ${ }^{1}$ Montse Solé, ${ }^{1,3}$ Robert C. Axtell, ${ }^{1}$ Thuy-Vi V. Nguyen,,${ }^{1,2}$ \\ @Gilberto J. Soler-Llavina, ${ }^{4}$ Sandra Jurado, ${ }^{4}$ Jullet Han, ${ }^{1}{ }^{\circ}$ Lawrence Steinman, ${ }^{1}$ Frank M. Longo, ${ }^{1}$ Julie A. Schneider, ${ }^{5}$ \\ Robert C. Malenka, ${ }^{4}$ and $\oplus^{-M a r i o n ~ S . ~ B u c k w a l t e r ~}{ }^{1,6}$ \\ ${ }^{1}$ Department of Neurology and Neurological Sciences, Stanford University School of Medicine, Stanford, California 94305, ${ }^{2}$ Department of Immunobiology, \\ Department of Neurology, and the Arizona Center on Aging, University of Arizona, Tucson, Arizona $85724,{ }^{3}$ Neurosciences Institute and Department of \\ Biochemistry and Molecular Biology, Medicine Faculty, Universitat Autonoma de Barcelona, Barcelona 08193, Spain, ${ }^{4}$ Nancy Pritzker Laboratory, \\ Department of Psychiatry and Behavioral Sciences, Stanford University School of Medicine, Stanford, California 94305, ${ }^{5}$ Department of Pathology and \\ Neurological Sciences, Rush Alzheimer's Disease Center Rush University Medical Center, Chicago, Illinois 60612, and ${ }^{6}$ Department of Neurosurgery, \\ Stanford University School of Medicine, Stanford, California 94305
}

Each year, 10 million people worldwide survive the neurologic injury associated with a stroke. Importantly, stroke survivors have more than twice the risk of subsequently developing dementia compared with people who have never had a stroke. The link between stroke and the later development of dementia is not understood. There are reports of oligoclonal bands in the CSF of stroke patients, suggesting that in some people a B-lymphocyte response to stroke may occur in the CNS. Therefore, we tested the hypothesis that a B-lymphocyte response to stroke could contribute to the onset of dementia. We discovered that, in mouse models, activated B-lymphocytes infiltrate infarcted tissue in the weeks after stroke. B-lymphocytes undergo isotype switching, and IgM, IgG, and IgA antibodies are found in the neuropil adjacent to the lesion. Concurrently, mice develop delayed deficits in LTP and cognition. Genetic deficiency, and the pharmacologic ablation of B-lymphocytes using an anti-CD20 antibody, prevents the appearance of delayed cognitive deficits. Furthermore, immunostaining of human postmortem tissue revealed that a B-lymphocyte response to stroke also occurs in the brain of some people with stroke and dementia. These data suggest that some stroke patients may develop a B-lymphocyte response to stroke that contributes to dementia, and is potentially treatable with FDA-approved drugs that target B cells.

Key words: B-lymphocyte; dementia; immunology; stroke

\section{Introduction}

The 7 million Americans currently living with the aftereffects of stroke are at increased risk of developing dementia, and approximately one-third will eventually suffer from vascular dementia (Barba et al., 2000; Leys et al., 2005; Béjot et al., 2011). In many of these patients, dementia might be caused by an associated comorbidity, but even after controlling for dementia risk factors, such as hypertension, hypercholesterolemia, diabetes, and age, the oc-

Received Oct. 2, 2014; revised Dec. 8, 2014; accepted Dec. 18, 2014.

Author contributions: K.P.D., L.N.Q., M.S., R.C.A., T.V.V.N., GJ.S.-L., S.J., J.H., L.S., F.M.L., J.A.S., R.C.M., and M.S.B. designed research; K.P.D., L.N.Q., M.S., R.C.A., T.V.V.N., G.J.S.-L., S.J., and J.H. performed research; J.A.S. contributed unpublished reagents/analytic tools; K.P.D., R.C.M., and M.S.B. analyzed data; K.P.D., J.A.S., and M.S.B. wrote the paper.

This work was supported by National Institutes of Health Grants R01NS067132 and R21NS078571 to M.S.B., Grant K99NR013593 to K.P.D., and Grant P30AG10161 to J.A.S., National Institute on Aging Grant R01AG017917 to J.A.S., as well as the Jean Perkins Foundation to F.M.L. and the Horngren Family Alzheimer's Research Fund to F.M.L. We thank Genentech Inc. for the gift of the anti-CD20 antibody; Ahmet Arac for providing tissue from mice that underwent intraluminal filament MCA0; Armine Garcia-Barker for help with immunostaining; and Katrin Andreasson, Tonya Bliss, and Ami Okada for critical review of the manuscript.

The authors declare no competing financial interests.

Correspondence should be addressed to Dr. Marion S. Buckwalter, Departments of Neurology and Neurological Sciences and Neurosurgery, Stanford University Medical School, 1201 Welch Road, Stanford, CA 94305. E-mail: marion.buckwalter@stanford.edu.

DOI:10.1523/JNEUROSCI.4098-14.2015

Copyright $\odot 2015$ the authors $\quad 0270-6474 / 15 / 352133-13 \$ 15.00 / 0$ currence of a single stroke increases the risk of developing new dementia by at least twofold (Leys et al., 2005; Savva and Stephan, 2010). The mechanism(s) behind this increased dementia risk are unknown.

We focused here on the hypothesis that stroke can elicit a chronic, injurious B-lymphocyte-mediated response that impairs cognition. In mice, immune responses are not well characterized beyond the first few weeks after stroke. However, in human stroke survivors, there is evidence of immunoglobulin synthesis in the CSF even weeks to months after stroke (Roström and Link, 1981; Tsementzis et al., 1986; Prüss et al., 2012). B-lymphocytes themselves have not previously been reported in human or mouse strokes, but B-lymphocyte aggregates occur in the meninges in both experimental autoimmune encephalomyelitis (EAE) in mice and multiple sclerosis (MS) in humans (Galea et al., 2007), and also in the lesion in a mouse model of spinal cord injury (Ankeny and Popovich, 2010). In the injured spinal cord, they produce autoantibodies that bind to nuclear antigens that can cross-react with neuronal antigens, and mice that lack B-lymphocytes have improved recovery (Ankeny et al., 2006; Ankeny and Popovich, 2010). Ectopic lymphoid tissues that contain B- and T-lymphocytes are also observed outside the CNS in both pathogenic and nonpathogenic chronic inflammatory states and correlate with increased severity of 
autoimmune disease or infection (Carragher et al., 2008; Varallyay et al., 2013).

To investigate the possibility that a B-lymphocyte-mediated immune response after stroke might mediate some of the increased risk of dementia in stroke survivors, we first asked whether chronic inflammation occurs weeks after stroke in wild-type mice. We characterized the immune response that was present 7 weeks after stroke, with particular attention to B-lymphocytes and antibodyproducing plasma cells. We next developed a mouse model of delayed cognitive decline after stroke using wild-type C57BL/6J mice and confirmed it in a second mouse strain, $\mathrm{BALB} / \mathrm{CJ}$ mice. We then used B-cell-deficient mice and a B-cell-depleting antibody to test the hypothesis that B-lymphocyte responses cause delayed cognitive impairment. Finally, we obtained brain tissue from human subjects that suffered from stroke and dementia and asked whether there was a difference in B-lymphocyte density and IgG immunoreactivity in the brain compared with controls. Our data indicate that mice develop a B-lymphocyte-mediated autoimmune response that causes delayed cognitive dysfunction and that some humans develop a similar response.

\section{Materials and Methods}

Mice. Adult mice were male, 3- to 5-months-old, C57BL/6J, muMT (C57BL/6J background, Jax stock \#002288), or BALB/CJ purchased from the The Jackson Laboratory. All procedures met National Institutes of Health guidelines with the approval of the Stanford University Institutional Animal Care and Use Committee.

Stroke surgery. In BALB/CJ mice, distal middle cerebral artery occlusion (DMCAO) was performed as previously described (Doyle et al., 2012). Sham surgeries were identical to stroke surgeries, except for ligation of the distal middle cerebral artery. C57BL/6J mice were given $8 \%$ oxygen for $1 \mathrm{~h}$ immediately after DMCAO. We refer to this variation of DMCAO as DH stroke (DMCAO + hypoxia). This period of hypoxia induces vasoconstriction and compensates for extensive collateralization between the anterior cerebral artery and middle cerebral artery present in C57BL/6J mice (Doyle et al., 2012).

For all experiments, mice received one dose of the antibiotic cefazolin, $25 \mathrm{mg} / \mathrm{kg}$ s.c., immediately after surgery. Mice that underwent sham DH stroke were also given $8 \%$ oxygen for $1 \mathrm{~h}$ immediately after surgery. DMCAO in BALB/CJ mice and DH stroke in C57BL/6J mice generate equivalent lesions (Doyle et al., 2012). Core body temperature was maintained at $37^{\circ} \mathrm{C}$ throughout surgery. Mice were returned to their cages with free access to food and water after closure of the surgical wound. Infarct assessment was performed as previously described using 2,3,5triphenyltetrazolium chloride staining (Doyle et al., 2012). Sixty minutes of transient proximal intraluminal filament middle cerebral artery occlusion (MCAO) was performed as previously described (Arac et al., 2011). For photothrombotic stroke, an incision was made on the top of the head to expose the skull. A 5-mm-diameter optic cable connected to a metal halide fiber-optic illuminator (Dolan-Jenner MH-100) was then placed on top of the skull using a stereotactic frame. Mice were injected intraperitoneally with $40 \mathrm{mg} / \mathrm{kg}$ Rose Bengal (Sigma, \#330000-5G) dissolved in saline, and $5 \mathrm{~min}$ later the light source was turned on for $15 \mathrm{~min}$.

Mouse immunohistochemistry and immunofluorescence. Hematoxylin and eosin staining and immunostaining were performed as described using standard techniques on PFA-fixed $40 \mu \mathrm{m}$ coronal brain sections (Doyle et al., 2010). Primary antibodies were against B220 (biotinylated, 1:500; BD Biosciences, 553085), CD11c (1:500; Abcam, ab33483), IgG (biotinylated, 1:1000; Vector, BA-2000), CD3 (1:500; BD Biosciences, 550277), MHCII (I-A/I-E, 1:500; BD Biosciences, 553621), CD68 (1: 1000; Serotec, MCA1957), and Ibal (1:1000; Wako, 019-19741). The specificity of primary antibody staining was confirmed using control sections treated with secondary antibody alone. For Table 1, cells were counted using National Institutes of Health ImageJ cell counting software in the stroke core in two sections per mouse $(n=6)$. For Figure $7 C$, quantification of CD3 immunostaining was performed on two sections per mouse blinded to treatment/genotype. Quantification of IgG immu-

\section{Table 1. Immune cells within the stroke lesion ${ }^{a}$}

\begin{tabular}{lc}
\hline Cell type & Cells per section (mean \pm SD) \\
\hline B-lymphocytes $\left(\mathrm{B} 220^{+}\right)$ & $1286 \pm 134$ \\
T-lymphocytes $\left(\mathrm{CD}^{+}\right)$ & $1226 \pm 128$ \\
$\mathrm{CD} 68^{+}$ & $11,174 \pm 1176$ \\
$\mathrm{MHCll}^{+}$ & $1487 \pm 1124$ \\
$\mathrm{CD}^{+} \mathrm{c}^{+}$ & $1786 \pm 1112$ \\
\hline
\end{tabular}

${ }^{a}$ Relative frequency of $\mathrm{T}$ - and B-lymphocytes, $\mathrm{CD} 68{ }^{+}$macrophages, $\mathrm{MHCII}{ }^{+}$cells, and $\mathrm{CD} 11 \mathrm{c}^{+}$cells within the stroke lesion 7 weeks following DH stroke in C57BL/6J mice $(n=6)$.

nostaining was performed in one section per mouse blinded to treatment. A photomicrograph of the region shown in Figure $8 E$ (black box) was assayed for mean gray value using ImageJ.

Brain flow cytometry. Cells were stained with fluorescent antibodies (CD3, CD19, and CD138) using standard techniques, analyzed using a FACScan flow cytometer (BD Biosciences) and quantified using FlowJo software (TreeStar). To isolate immune cells in the brain 7 weeks following stroke, we pooled 10 mice and incubated brain homogenates with collagenase (Roche) and DNase (Sigma) for $1 \mathrm{~h}$ at $37^{\circ} \mathrm{C}$ and purified the cells by Percoll gradient centrifugation. Cells were gated by forward scatter and side scatter to identify lymphocytes, using spleen as a control. For Figure $1 E$, cells were subsequently gated by CD19 high expression.

ELISA identification of antibody isotypes in the brain. Seven weeks following stroke or sham surgery, mice were perfused with saline, and the cortex and hippocampus were dissected. Tissue was immersed in lysis buffer (Sigma CelLytic MT Mammalian Tissue Lysis Reagent containing Sigma protease inhibitor mixture and Sigma phosphatase inhibitor mixture 2) at a ratio of 1:20 and sonicated. Following centrifugation, the protein concentration of the supernatant was calculated and normalized to $10 \mathrm{mg} / \mathrm{ml}$. Antibody concentrations in the cortex and hippocampus were then measured using a rapid ELISA mouse antibody isotyping kit (Thermo Scientific) according to the manufacturer's instructions (sham $n=3$, stroke $n=5-7$ ).

Multiplex immunoassay for quantifying cytokine and antibody concentrations in plasma and in the stroke lesion. After stroke or sham surgery, $100-400 \mu$ l blood was collected by cardiac puncture under anesthesia, placed in EDTA tubes, and centrifuged to obtain plasma. Mice were then perfused with sterile saline, and dissected brain tissue immersed in lysis buffer (Sigma CelLytic MT Mammalian Tissue Lysis Reagent containing Sigma protease inhibitor mixture and Sigma phosphatase inhibitor mixture 2) at a ratio of 1:20 and sonicated. Following centrifugation, the protein concentration of the supernatant was calculated and normalized to $1 \mathrm{mg} / \mathrm{ml}$. Cytokines, chemokines, and antibody isotypes were then detected and quantified by multiplex immunoassay. Mouse multiplex kits were purchased from Affymetrix and Millipore and used according to the manufacturer's recommendations. Each sample was measured in duplicate. Plates were read using a Luminex instrument, and results were analyzed using Prism software.

Acute slice preparation and whole-cell recordings. Mice were decapitated after deep isoflurane anesthesia. The forebrain was removed and placed in ice-cold dissection media consisting of $228 \mathrm{~mm}$ sucrose, $26 \mathrm{~mm}$ $\mathrm{NaHCO}_{3}, 11 \mathrm{~mm}$ glucose, $7.0 \mathrm{~mm} \mathrm{MgSO}_{4}, 2.5 \mathrm{~mm} \mathrm{KCl}, 1.0 \mathrm{~mm} \mathrm{NaH}_{2} \mathrm{PO}_{4}$, and $0.5 \mathrm{mM} \mathrm{CaCl}_{2}$. Coronal slices from the dorsal hippocampus were cut in $225-\mu \mathrm{m}$-thick sections using a vibratome (Leica, VT1200S) and transferred to an incubation chamber containing artificial CSF (ACSF) consisting of $122 \mathrm{~mm} \mathrm{NaCl}, 26 \mathrm{~mm} \mathrm{NaHCO}_{3}, 11 \mathrm{~mm}$ glucose, $2.5 \mathrm{~mm} \mathrm{CaCl}_{2}$, $2.5 \mathrm{~mm} \mathrm{KCl}, 1.3 \mathrm{~mm} \mathrm{MgCl}_{2}$, and $1.0 \mathrm{~mm} \mathrm{NaH}_{2} \mathrm{PO}_{4}$. Slices were incubated for $30 \mathrm{~min}$ at $32^{\circ} \mathrm{C}$ and then kept at room temperature until use. Experiments were performed $1-5 \mathrm{~h}$ after the incubation period. Slices were transferred to a submerged recording chamber perfused with ACSF $\left(28^{\circ} \mathrm{C}-30^{\circ} \mathrm{C}\right)$. Picrotoxin $(50 \mu \mathrm{M}$ dissolved in DMSO, Sigma) was added to block inhibitory currents. Pyramidal neurons in the CA1 layer were visualized by infrared differential interference contrast on an upright microscope (Olympus BX51WI). Whole-cell recordings from these cells were obtained with patch electrodes containing $117.5 \mathrm{~mm}$ cesium methanesulfonate, $15.5 \mathrm{~mm} \mathrm{CsCl}, 10 \mathrm{~mm}$ TEA-Cl, $10 \mathrm{~mm}$ HEPES buffer, $10 \mathrm{~mm}$ sodium phosphocreatine, $8 \mathrm{~mm} \mathrm{NaCl}, 5 \mathrm{~mm}$ EGTA, 1 mM $\mathrm{MgCl}_{2}, 4 \mathrm{~mm}$ Mg-ATP, $0.3 \mathrm{~mm} \mathrm{Na}-\mathrm{GTP}$, and $1 \mathrm{~mm}$ QX-314. Electrode resistances 


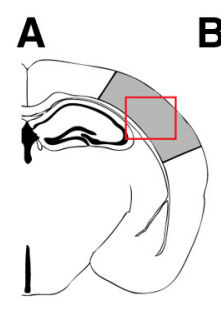

F

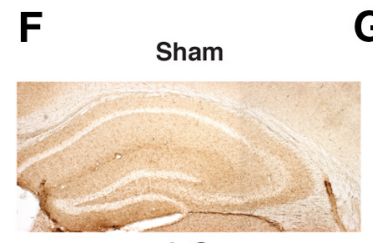

IgG

1

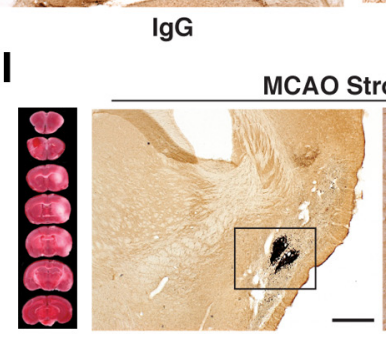

B

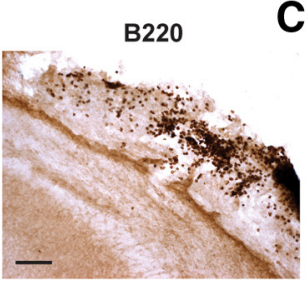

C

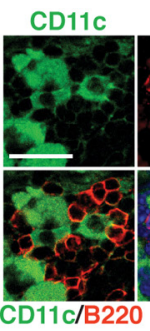

B220

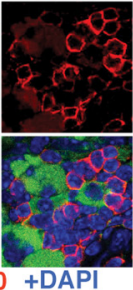

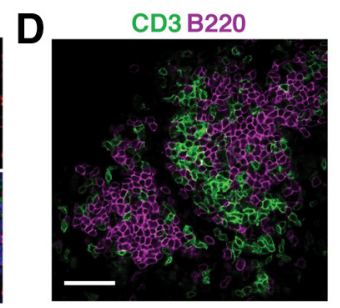

H
G Stroke

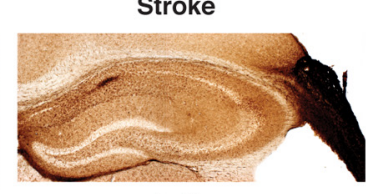

$\lg G$

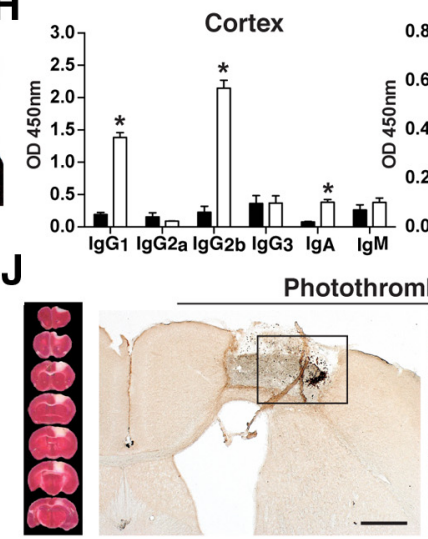

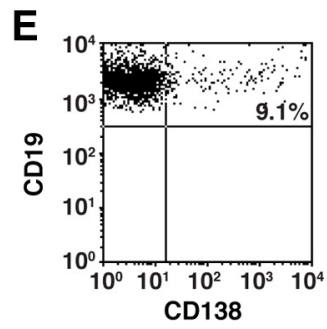

Hippocampus

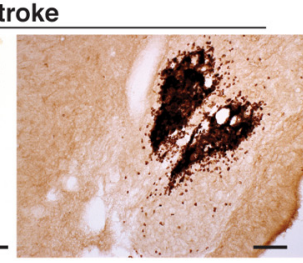

J

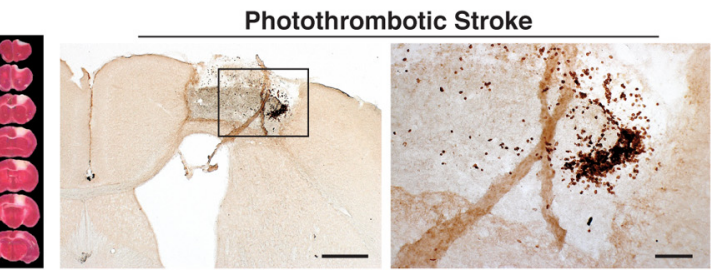

Figure 1. A B-lymphocyte response to stroke occurs in C57BL/6J mice. $A$, Schematic diagram of a mouse coronal brain section following DH stroke, with the stroke core shaded in gray and a red box to indicate the region immunostained in $\boldsymbol{B}-\boldsymbol{D}$, and used for flow in $\boldsymbol{E}$. $\boldsymbol{B}$, Immunostaining for B220 (B-lymphocytes) shows that B cells are present in the lesion 7 weeks following DH stroke in C57BL/6J mice. Scale bar, $250 \mu \mathrm{m}$. C, Fluorescent immunostaining for the B-lymphocyte marker B220 (red) and the dendritic cell marker CD11c (green) shows that B cells are still present in the lesion 12 weeks following stroke and are juxtaposed to cells immunostaining for CD11c. Scale bar, $25 \mu \mathrm{m}$. Images are representative of 10 mice that underwent stroke. D, Fluorescent immunostaining for the B-lymphocyte marker B220 (magenta) and the T-cell marker CD3 (green) reveals that B cells and T cells are compartmentalized 7 weeks following DH stroke. Scale bar, $100 \mu \mathrm{m}$. E, Flow cytometry revealed that $9 \%$ of $\mathrm{CD} 19^{+}$B-lymphocytes present in the stroke lesion were $\mathrm{CD} 19^{+} \mathrm{CD} 138^{+}$plasma cells $(n=10$ pooled stroke lesions). $\boldsymbol{F}, \boldsymbol{G}$, Representative images of IgG immunostaining in the hippocampus 7 weeks following stroke or sham surgery $(n=10)$. $\boldsymbol{H}$, Determination of antibody isotypes present in the cortex and hippocampus 7 weeks following stroke or sham surgery (stroke $n=7$; sham $n=3) .{ }^{*} p<0.05$, compared with sham. Error bars indicate SD. I, J, Immunostaining for the B-cell marker B220 4 weeks after stroke in two additional stroke models performed in C57BL/6J mice: MCA0 (I) and photothrombotic stroke (PT stroke) (J). Scale bars, 500 and $100 \mu \mathrm{m}$ (lower and higher magnifications, respectively).

ranged from 2.5 to $4.5 \mathrm{M} \Omega$. To record EPSCs, cells were held at $-70 \mathrm{mV}$ while stimulating the Schaffer collaterals (at $0.1 \mathrm{~Hz}$ ) with small, brief current pulses (10-50 $\mu \mathrm{A}, 0.2 \mathrm{~ms})$ using a double-barreled glass pipette (theta glass, Warner) filled with ACSF. Following a 5 min baseline period, LTP was induced by two trains of high-frequency stimulation $(100 \mathrm{~Hz}$, $1 \mathrm{~s}$ ) separated by $20 \mathrm{~s}$ while holding the cells at $0 \mathrm{mV}$. The induction protocol was always applied within 10 min of achieving whole-cell configuration, to avoid "wash-out" of LTP. Following induction, stimulation at $0.1 \mathrm{~Hz}$ was resumed and the EPSC amplitude monitored for $50 \mathrm{~min}$.

Electrophysiological data acquisition and analysis. EPSCs were recorded in a whole-cell voltage clamp (Multiclamp 700B, Molecular Devices), filtered at $4 \mathrm{kHz}$, and digitized at $10 \mathrm{kHz}$ (ITC-18 interface, HEKA). Series resistance and whole-cell capacitance were not compensated. All electrophysiological data were acquired and analyzed using the Recording Artist package (Dr. Rick Gerkin) written in Igor Pro (Wavemetrics). To generate LTP summary time course graphs, individual experiments were normalized to the baseline and six consecutive responses were averaged to generate $1 \mathrm{~min}$ bins. The binned time courses of all experiments within a group were then averaged to generate the final graphs. The magnitude of LTP was calculated based on the normalized EPSC amplitudes 46-50 min after the end of the induction protocols.

$Y$ maze spontaneous alternation test. Mice were tested in a Y-shaped maze with three white, opaque plastic arms set at a $120^{\circ}$ angle from each other. Mice were placed in the center of the maze and allowed to freely explore the three arms for 5-8 min until 20 entries had been achieved. Over the course of multiple entries, normal mice typically exhibit a tendency to visit new arms of the maze rather than visiting a recently visited arm. An entry was recorded when all four limbs of the mouse were within an arm. The number of arm entries and the number of triads were recorded to calculate the percentage of spontaneous alternation.
Object location test (OLT). Mice were habituated to an empty arena containing spatial cues on the walls for $5 \mathrm{~min}$. Mice were then returned to their home cage while four objects were placed in the arena. The objects were children's building blocks of different shapes and colors, and each was placed in a corner of the arena, $5 \mathrm{~cm}$ from the walls. Mice were allowed to explore the objects for $5 \mathrm{~min}$ and then were returned to their home cage. The positions of two of the objects were then switched. Mice were returned to the arena, and the number of rears on each object was recorded for a further $5 \mathrm{~min}$. This test is based on the spontaneous tendency of rodents to spend more time exploring an object that has been relocated.

Treatment with anti-CD20 antibody. Mice were injected in the tail vein with $10 \mathrm{mg} / \mathrm{kg}$ anti-CD20 antibody (clone 5D2, isotype IgG2a, Genentech), or isotype control (anti-ragweed IgG2a, Genentech) beginning $5 \mathrm{~d}$ after stroke or sham surgery $(n=10$ per group). Drug treatment was repeated every 2 weeks thereafter, and B-cell ablation was monitored every $7 \mathrm{~d}$ after drug treatment by flow cytometric analysis of a tail blood sample from each mouse using antibodies against CD3 (T-lymphocytes) and CD19 (B-lymphocytes).

Human tissue. Paraffin-embedded human brain sections from the stroke core of subjects with vascular dementia and stroke were obtained from the Rush Religious Orders Study (16 subjects) (Bennett et al., 2012a) and the Rush Memory and Aging Project (5 subjects) (Bennett et al., 2012b). Tissue was from 21 stroke patients of mixed gender. Hematoxylin and eosin sections superficial and deep to the lesion were studied to ensure that infarcted tissue was within the sections used for study. Frontal cortex sections from 9 age-matched controls that did not have either stroke or dementia were also provided. Tissue was immunostained using standard techniques with an anti-CD20 antibody (1:500; Dako M0755). Total CD20 ${ }^{+}$cells present in each slide were counted and divided by the area of tissue present on the slide to obtain the number of 

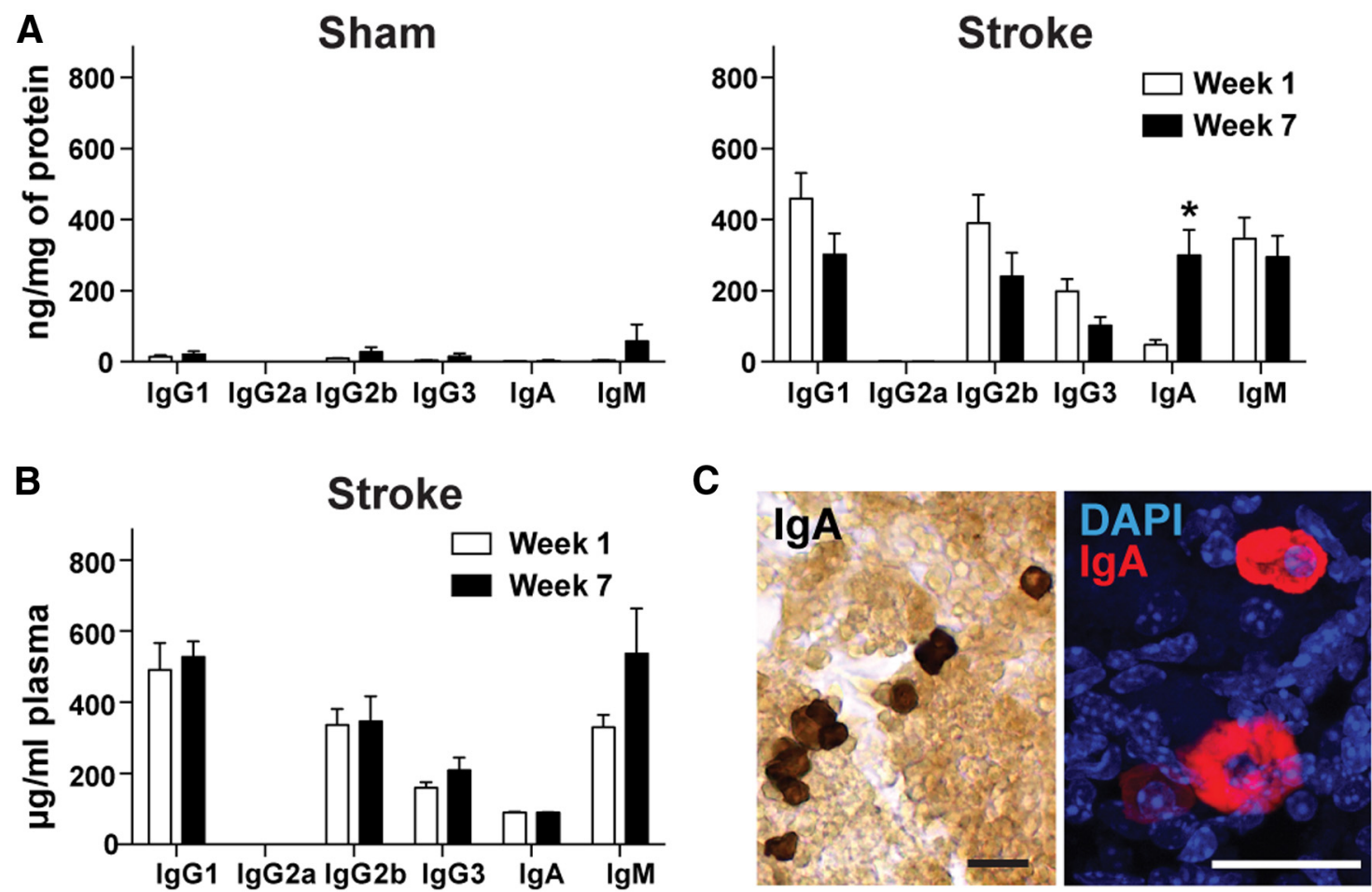

Figure 2. There is a delayed appearance of $\lg A$ in the brain but not the blood between 1 and 7 weeks after stroke. $A$, Multiplex immunoassay revealed that the amount of IgA present in the ipsilateral hemisphere significantly increased between week 1 and week 7 after stroke ( $n=4-7$ per group). ${ }^{*} p<0.05$, compared with 1 week (two-way ANOVA). Error bars indicate mean \pm SEM. $B$, There was no difference in immunoglobulin content in the plasma at week 1 and week 7 after stroke. There was no difference between stroke and sham plasma at week 1 and 7 after stroke (data not shown). C, IgA immunostaining (left: DAB, right: fluorescence) revealed the presence of IgA-producing plasma cells in the stroke lesion 7 weeks following stroke $(n=7)$. Scale bars, $75 \mu \mathrm{m}$.

B-lymphocytes $/ \mathrm{cm}^{2}$. Immunostaining for IgG was performed with biotinylated anti-human IgG (1:1000; Vector, BA-3000).

Statistical analysis. All animal experiments were designed to ensure humane endpoints and minimize numbers of mice and suffering. Allocation of mice into stroke and sham groups was performed randomly, and behavior experiments were performed with the experimenter blind to treatment group. For immunostaining and electrophysiology, blinding was not possible because of the stroke lesion being clearly visible in the stroke groups. Data are expressed as mean \pm SEM unless otherwise indicated in the figure legend. Statistical analyses were performed with Prism 5 software (GraphPad). Means between two groups were compared with a two-tailed, unpaired Student's $t$ test, except in the case of B-cell densities, which were compared by a Mann-Whitney test. Differences in cytokine/chemokine expression in the lesion of WT and muMT mice and in antibody isotype concentrations in mouse brain were compared using a two-way ANOVA. Kruskal-Wallis ANOVA and Mann's post hoc analysis was used to compare B-cell densities in $\mathrm{IgG}^{+}$and $\mathrm{IgG}^{-}$ subjects with control.

\section{Results}

To determine whether a B-lymphocyte response develops in the brain after stroke and contributes to delayed cognitive impairment, we searched for a mouse model of stroke that does not cause immediate cognitive impairment and thus could be used to look for the development of delayed cognitive deficits.

The most commonly used mouse stroke model, intraluminal filament MCAO, can cause immediate cognitive impairment, making it difficult to detect or study any delayed symptoms that might result from an adaptive immune response to stroke (Hattori et al., 2000; Truong et al., 2012). However, from our previous work (Doyle et al., 2012), we identified an experimental stroke paradigm: the $\mathrm{DH}$ stroke model in $\mathrm{C} 57 \mathrm{BL} / 6 \mathrm{~J}$ mice that produces a lesion adjacent to, but not incorporating, the hippocampus and does not cause immediate cognitive impairment. This character- istic renders this model ideal for studying stroke-induced dementia. DH stroke creates a large lesion comprising $25 \%$ of the stroked hemisphere, has little variability, and excellent long-term survivability (Doyle et al., 2012).

We discovered that there is substantial delayed infiltration of B-lymphocytes into infarcted tissue in the weeks after DH stroke. B-lymphocytes are virtually undetectable in the lesion 1 week after stroke ( $<1$ cell per $40-\mu$ m-thick coronal brain section), but there is extensive infiltration at 7 weeks that is still present at 12 weeks following stroke (Fig. $1 A-C$ ). B-lymphocytes are surrounded by cells expressing the dendritic cell marker CD11c (Fig. $1 C)$. Dendritic cells can transfer antigen to naive $\mathrm{B}$ cells to initiate antigen-specific antibody responses and can provide $B$ cells with isotype-switching signals (Wykes and MacPherson, 2000). Additionally, we observed that whenever T cells and B cells were clustered together, they were compartmentalized. B cells formed the center of each cluster and were surrounded by a ring of T cells (Fig. 1D). A total of $9 \%$ of the $\mathrm{CD} 19^{+}$B-lymphocytes coexpressed CD138, a marker of immunoglobulin-synthesizing plasma cells (Fig. 1E).

To test whether the plasma cells in the stroke lesion were producing antibodies, we immunostained brain tissue from mice killed 7 weeks after stroke with an anti-mouse IgG secondary antibody. Immunostaining demonstrated extensive IgG in both the stroke lesion and the area adjacent to the stroke lesion, which includes the hippocampus (Fig. $1 F, G$ ). Immunostaining was most intense near the stroke lesion, suggesting that antibody might be diffusing from the lesion across the glial scar into the hippocampus and neighboring tissue. A similar finding has been reported after spinal cord injury (Ankeny et al., 2009; Ankeny and Popovich, 2010); however, it might also be diffusing from the bloodstream into this tissue if there is blood-brain barrier dysfunction in this location. In some mice, the pattern of immuno- 


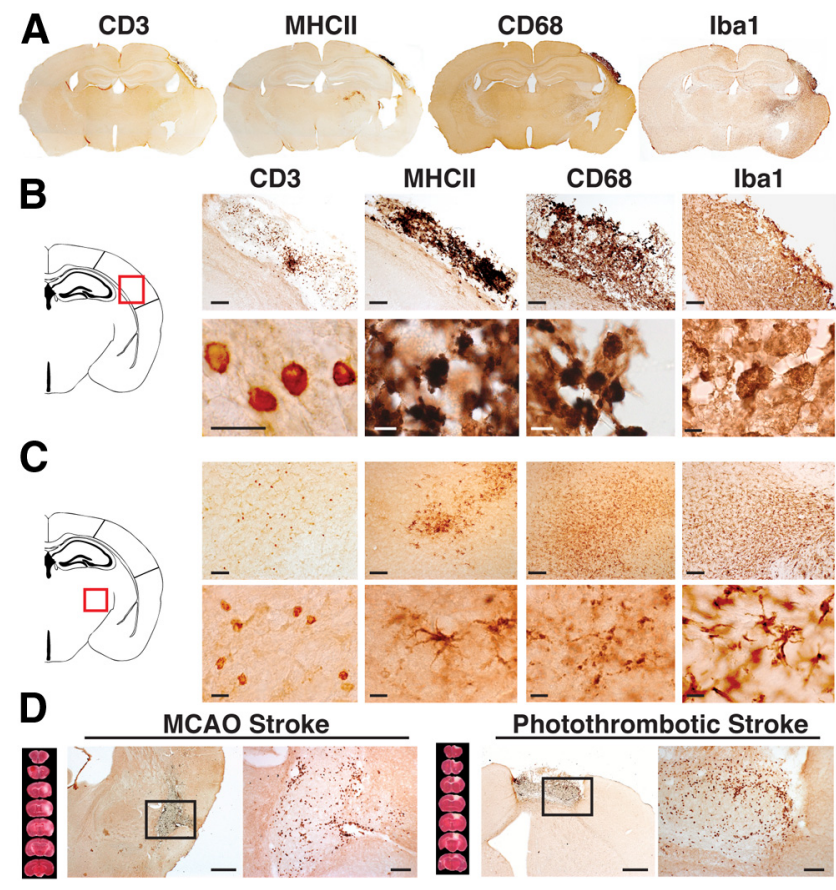

Figure 3. The B-lymphocyte response to stroke is a component of a larger adaptive immune response to stroke. $\boldsymbol{A}$, Whole-brain sections showing the locations of $\mathrm{T}$ cells $\left(\mathrm{CD}^{+}{ }^{+}\right), \mathrm{MHCll}$ expression, and activated macrophages/microglia $\left(\mathrm{CD} 68^{+}\right.$and lba $\left.1^{+}\right) 7$ weeks after stroke. Staining is evident both in the lesion and locations where there is axonal degeneration. Images are representative of 10 mice. $B, C$, Progressively higher-magnification images of $C D 3, M H C I I$, CD68, and lba1 staining in the lesion $(\boldsymbol{B})$ and in an area of axonal degeneration (C). Equivalent findings were observed in two additional independent experiments. $\boldsymbol{D}$, Equivalent T-cell responses after stroke were also independently observed with CD3 immunostaining in two additional stroke models: $M C A 0$ and photothrombotic stroke. This demonstrates that an adaptive immune response to stroke is not model-dependent in (57BL/6J mice. Scale bars: B, C, $250 \mu \mathrm{m}$, $10 \mu \mathrm{m} ; \boldsymbol{D}, 500 \mu \mathrm{m}, 100 \mu \mathrm{m}$ (lower and higher magnifications, respectively).

staining was suggestive of autoantibodies binding to cells in the pyramidal cell layer. The pattern of staining was, however, variable from mouse to mouse.

To identify which antibody isotypes were present in the brain after stroke, we performed a mouse antibody isotyping ELISA. We discovered that, in both the lesion and adjacent hippocampus, the majority of the antibody was IgG (IgG1 and IgG2b), although IgM and IgA were also present (Fig. $1 H$ ). A B-lymphocyte response to stroke was a consistent finding, seen in the stroke core of every mouse in each experiment, and also in two additional, distinct, stroke models: MCAO and photothrombotic stroke (Fig. $1 \mathrm{I}, \mathrm{J}$ ).

To more precisely quantify antibody infiltration into the brain after stroke and to look for evidence of B-cell activation in the form of isotype switching between weeks 1 and 7 after stroke, we performed a multiplex immunoassay for IgG1, IgG2a, IgG2b, IgG3, IgA, and IgM on brain tissue taken from mice following stroke or sham surgery. The amount of antibody present in the brain at both 1 and 7 weeks after stroke was approximately equivalent, and it was absent in mice that underwent sham surgery (Fig. 2A). This indicates that either antibody is not cleared from the brain in the weeks following stroke once it enters the brain following acute BBB disruption, or that it persistently diffuses into the brain from the site of the stroke lesion. In support of the latter, the amount of IgA present in the brain increased significantly between week 1 and week 7 (Fig. 2A). This also indicates that stroke leads to isotype switching in plasma cells.

To determine whether some of the antibody we observe in the brain following stroke has a blood-borne or local source, we used a multiplex immunoassay to quantify immunoglobulin in the plasma of C57BL/6 mice killed 1 and 7 weeks following stroke, and an immunostain to look for IgA-producing plasma cells within the stroke lesion 7 weeks following stroke. There was no detectable increase in IgA within the plasma in the weeks following stroke (Fig. 2B), and IgA-positive cells were present within the lesion (Fig. 2C). This suggests that, although some of the antibody present in the brain in the weeks following stroke may be from the blood, at least some of the IgA in the brain at late time points after stroke is locally produced from plasma cells within the lesion.

The initial activation of B-lymphocytes, and subsequent isotype switching, is predominantly T-cell dependent (Bishop and Hostager, 2001). Therefore, to investigate whether our discovery of a B-lymphocyte response to stroke is part of a larger adaptive immune response to stroke, we looked for the presence and relative abundance of T cells, MHCII expression, and markers of activated microglia/macrophages in the brain 7 weeks following stroke. We discovered that stroke lesions contain abundant T-lymphocytes $\left(\mathrm{CD}^{+}\right)$, MHCII-expressing cells, and activated microglia/macrophages $\left(\mathrm{CD} 68^{+}, \mathrm{Ibal}^{+}\right)$at this time point (Fig. $3 A, B$; Table 1 ) as well as at 12 weeks following stroke (data not shown). Interestingly, in contrast to the strict localization of $B$ cells within stroke lesions, T cells, MHCII expression, and markers of activated microglia/macrophages (CD68 and MHCII), were also detected in the thalamus, striatum, and internal capsule of each mouse 7 weeks after stroke $(n=10)$. These locations normally contain the axons of neurons that project from the sensorimotor cortex (McGeorge and Faull, 1989), which is the cortical region that has undergone stroke in these mice. Also, at 7 weeks after injury, Wallerian degeneration is ongoing (Vargas and Barres, 2007). This may then mean that, where slow axonal degeneration occurs, there is a chronic inflammatory response around degenerating axons for weeks after the stroke (Fig. 3C). We did not find $\mathrm{B}$ cells in this region (data not shown). CD3 ${ }^{+}$ $\mathrm{T}$-cell infiltration in the brain was also observed 4 weeks following MCAO and photothrombotic stroke (Fig. 3D), demonstrating that the adaptive immune response identified with $\mathrm{DH}$ stroke is not stroke model specific.

Much of the antibody that is present in the mouse brain 7 weeks after DH stroke is in the hippocampus (Fig. $1 F, G$ ). LTP is one of the main neural mechanisms by which memory is stored in the hippocampus (Lynch, 2004). To determine whether antibody binding in this region impairs LTP, EPSCs were recorded from CA1 pyramidal neurons following stimulation of Schaffer collaterals projecting from CA3 pyramidal neurons. LTP was not impaired 1 week after stroke, a time point when few B cells are detectable in the lesion. Seven and 12 weeks after stroke, when there is extensive B-cell infiltration in the lesion and antibody infiltration in the hippocampus, there was significant and progressive impairment of LTP (Fig. $4 A, B$ ).

To determine whether the impaired LTP impacted cognition, we examined whether mice developed a memory deficit in the weeks after stroke. We used the Y maze, a hippocampal-dependent spatial memory task that measures the preference of rodents to explore a novel environment, and relies on their ability to remember which arms of the maze they have previously explored. Between weeks 1 and 7 following stroke, coincident with B-cell accumulation, mice developed a short-term memory deficit (Fig. 4C).

To verify that delayed cognitive impairment after stroke was generalizable to other models and not solely a function of the $\mathrm{DH}$ stroke model or of the C57BL/6J mouse strain, BALB/CJ mice underwent DMCAO stroke. The lesion following DMCAO in 


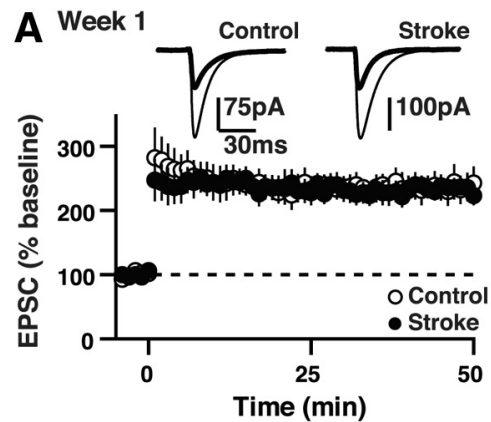

B

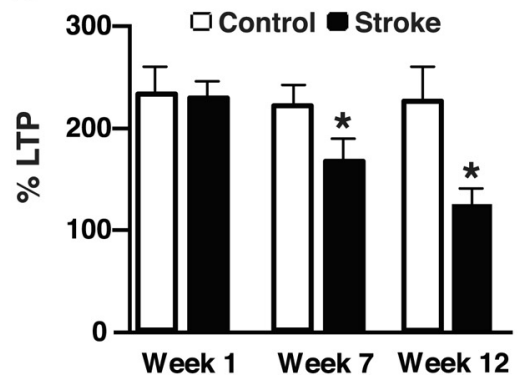

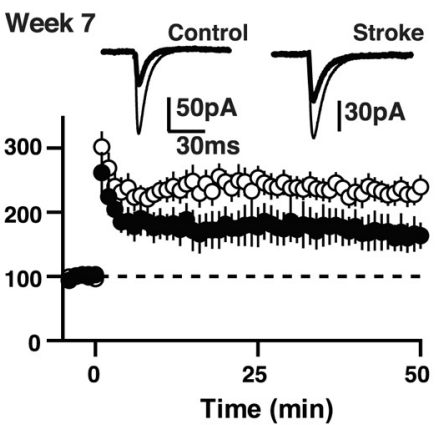

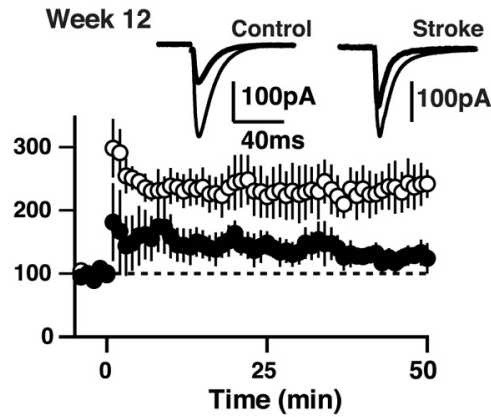

C

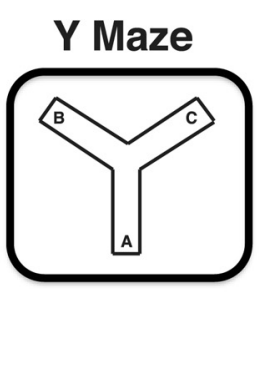

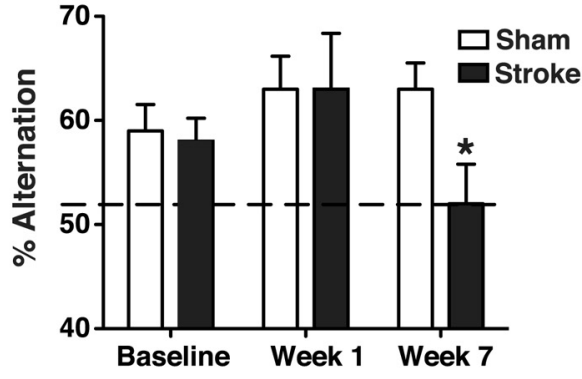

Figure 4. Mice develop a deficit in LTP in the hippocampus between weeks 1 and 7 after stroke, and a delayed cognitive deficit on the Y maze. $\boldsymbol{A}, \boldsymbol{B}$, Whole-cell EPSCS were recorded from CA1 pyramidal neurons in acute hippocampal slices prepared from (57BL/6J mice that had undergone stroke or sham surgery 1,7 , and 12 weeks earlier $(n=6-9$ per group). The time course $(\boldsymbol{A})$ and magnitude $(\boldsymbol{B})$ of LTP are illustrated and demonstrate an impairment at 7 and 12 weeks, but not 1 week, following stroke. ${ }^{*} p<0.05$, compared with controls. $\boldsymbol{C}, C 57 \mathrm{BL} / 6 \mathrm{~J}$ mice developed a delayed cognitive deficit on the $Y$ maze, a test of short-term memory, between weeks 1 and 7 following stroke ( $n=10$ per group). ${ }^{*} p<0.05$, compared with sham week 7 . Error bars indicate SD.

$\mathrm{BALB} / \mathrm{CJ}$ mice is equivalent in size and location to the lesion following $\mathrm{DH}$ stroke in $\mathrm{C} 57 \mathrm{BL} / 6 \mathrm{~J}$ mice (Fig. 5A), due to strain differences in cerebral vascular anatomy (Doyle et al., 2012). Importantly, DMCAO stroke in BALB/CJ mice does not involve hypoxia. In contrast, during $\mathrm{DH}$ stroke mice undergo $60 \mathrm{~min}$ of hypoxia. This duration of hypoxia does not directly injure the hippocampus (Doyle et al., 2012), and all sham controls in DH experiments experience the same duration of hypoxia.

Similarly to C57BL/6J mice after DH stroke, BALB/CJ mice exhibit $\mathrm{B}$ cells and $\mathrm{T}$ cells in the lesion 7 weeks following DMCAO (Fig. $5 B$ ). There was also substantial IgM, IgG, and IgA in the brain at weeks 1 and 7 after stroke (Fig. $5 C$ ). Furthermore, again similar to C57BL/6J mice following DH stroke, the amount of IgA present in the brain increased significantly between week 1 and week 7. This demonstrates that B-cell, T-cell, and antibody infiltration into the brain, as well as isotype switching after stroke, is not dependent on the hypoxia component of DH stroke. It also demonstrates that these responses are not strain specific.

BALB/CJ mice were not able to perform the Y maze task after either sham or stroke surgery due to freezing. However, they were able to perform another test of hippocampal function, the OLT, which is based on the ability of mice to remember the prior location of an object and recognize when it has been moved. They performed normally at baseline and 2 weeks following DMCAO and sham surgery (Fig. 5D). BALB/CJ mice that underwent sham surgery also performed normally 7 weeks following sham surgery. However, $\mathrm{BALB} / \mathrm{CJ}$ mice that underwent DMCAO were unable to perform this test 7 weeks following stroke. This demonstrates that the hypoxia component of DH stroke is not necessary for delayed cognitive dysfunction to occur after stroke.

To test the hypothesis that B-lymphocytes contribute to the development of the delayed onset short-term memory deficit, perhaps through antibody accumulation in the hippocampus and the binding of autoreactive antibodies (Kowal et al., 2004), muMT mice that lack mature B-lymphocytes underwent stroke and memory testing. muMT mice indeed did not develop a delayed LTP deficit (Fig. 6A,B), or a cognitive deficit on either hippocampal memory task, the OLT and the Y maze (Fig. $6 C, D$ ).

To investigate the mechanism by which muMT mice are protected from delayed cognitive dysfunction following stroke, we compared lesion size, B-cell and antibody infiltration, T-cell infiltration, and cytokine expression in muMT mice and WT mice. Infarct volumes $72 \mathrm{~h}$ following stroke were equivalent in $m u M T$ and WT mice (Fig. 7A). Also, as expected, we did not detect B cells or IgG in the stroke lesion in muMT mice (Fig. $7 B$ ). However, $\mathrm{T}$-cell infiltration and the production of proinflammatory cytokines and chemokines were equivalent in the lesion in muMT and WT mice 7 weeks after stroke (Fig. 7C,D). These data suggest that the mechanism by which B cells cause cognitive impairment after stroke is antibody mediated, rather than by an effect on T cells or cytokine production.

To investigate the translational potential of ablating B-lymphocytes after stroke, we tested whether ablating B cells using an anti-CD20 antibody could also prevent the emergence of delayed cognitive deficits. Based on our finding that it took longer than 1 week after stroke for most B-lymphocytes to infiltrate the brain, we initiated treatment five days after stroke. Mice received either a B-lymphocyte-depleting monoclonal anti-CD20 antibody (Kozakiewicz et al., 2013), or an isotype control antibody, via tail vein injection every 2 weeks following the first injection, for a total of 6 weeks. Anti-CD20 antibody treatment successfully ablated B cells in the circulation (Fig. $8 A, B$ ), prevented the appearance of delayed cognitive deficits (Fig. $8 C$ ), and prevented the recruitment of B cells and IgG to the brain (Fig. $8 D-F$ ). None of these effects was observed in mice treated with the control antibody. Anti-CD20 antibody treatment did not ablate T cells in the circulation (Fig. $8 A$ ) or alter T-cell recruitment to brain after stroke (data not shown).

Finally, to determine whether this new mouse model might be relevant to human post-stroke dementia, we evaluated 
A

A

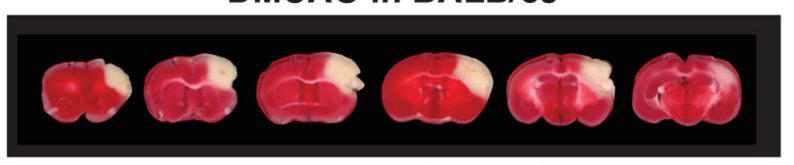

DH stroke in C57BL/6J

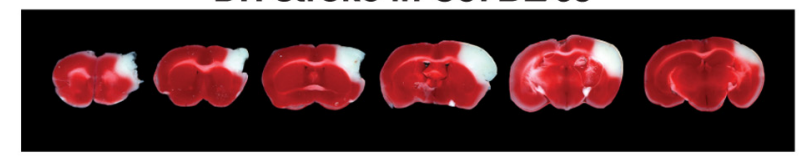

Lesion size in BALB/CJ and C57BL/6J mice after DMCAO and DH stroke

\begin{tabular}{lccc}
\hline Strain & Stroke Model & $\begin{array}{c}\text { Lesion Volume } \\
(\% \text { of hemisphere })\end{array}$ & SD \\
\hline BALB/cJ & DMCAO & $24 \%$ & $3.9 \%$ \\
C57BL/6J & DH stroke & $25 \%$ & $3.4 \%$ \\
\hline
\end{tabular}

B

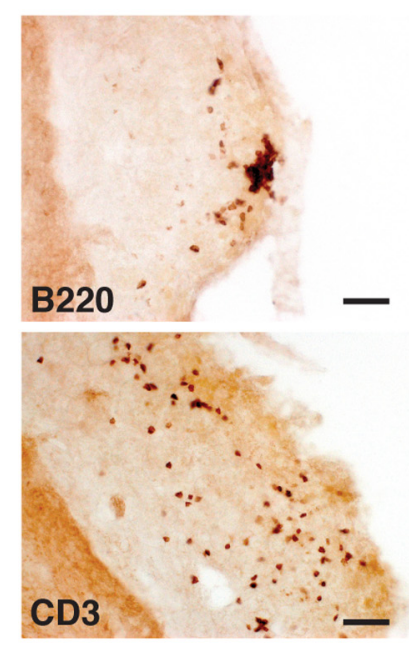

Stroke

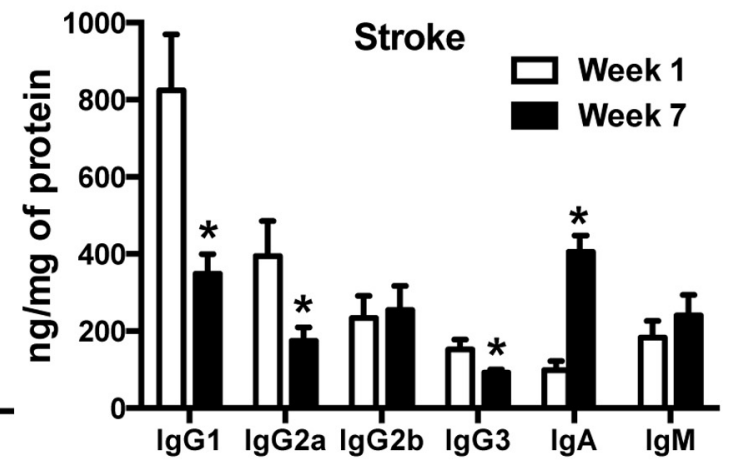

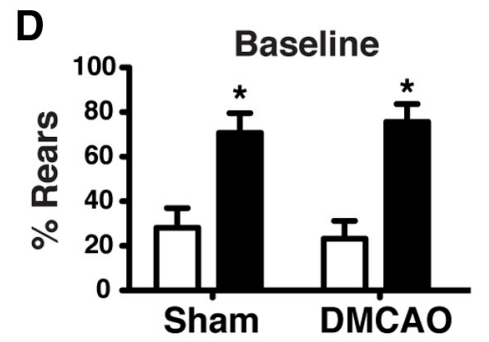
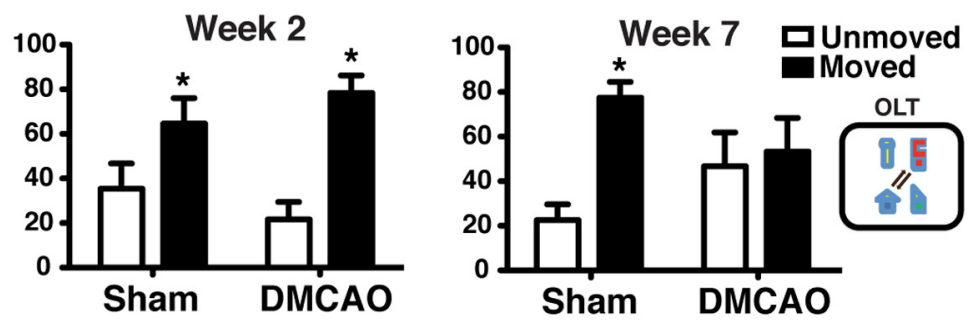

Figure 5. A B-lymphocyte response to stroke and delayed cognitive dysfunction also occurs in $B A L B / U$ mice. $A$, Lesion size and location are equivalent following DMCAO in $B A L B / C$ mice to lesion size and location following DH stroke in C57BL/6J mice. B, Immunostaining for the B- and T-lymphocyte markers B220 and CD3 in the stroke lesion 7 weeks after stroke. Scale bars, $100 \mu \mathrm{m}$. C, Quantification of immunoglobulins in the ipsilateral hemisphere in BALB/U mice 1 and 7 weeks after stroke $\left(n=10\right.$ pergroup). ${ }^{*} p<0.05$, compared with 1 week (two-way ANOVA). Error bars indicate mean \pm SEM. $D, B A L B / C$ mice also develop a delayed cognitive deficit on the 0 LT between weeks 1 and 7 after stroke ( $n=10$ per group). ${ }^{*} p<0.05$, moved versus unmoved objects.

B-lymphocyte responses in human postmortem brain tissue from the Rush Religious Orders Study and Rush Memory and Aging Project (Bennett et al., 2012a, b; Boyle et al., 2013). Our criteria were the presence of infarct and no pathologic diagnosis of Alzheimer's disease or other neuropathological disorder. Controls were matched subjects without stroke or dementia. We immunostained sections containing ischemic infarcts with CD20 to detect B cells (Fig. 9A).

We discovered $\geq 1$ B-lymphocytes $/ \mathrm{cm}^{2}$ in the stroke core and area adjacent to the stroke core in 19 of 21 subjects (Fig. 9; Table 2). Nine of the subjects had 1-10 B-lymphocytes $/ \mathrm{cm}^{2}$ in the ischemic area, 9 exhibited 11-100, and 1 had $>100$ B-lymphocytes $/ \mathrm{cm}^{2}$. In 9 control subjects, B-lymphocyte density ranged from 0 to $3.6 \mathrm{lym}$ phocytes $/ \mathrm{cm}^{2}$, significantly different from those with stroke (Fig. $9 B$ ). These results suggest that a B-lymphocyte response to stroke occurs in the CNS after stroke in some people.

Furthermore, IgG immunostaining revealed that antibodies are present in the brain in stroke survivors to a greater extent than in controls. Control brains uniformly contained IgG in the white mat- ter, vasculature, and meninges, with little to no immunostaining in the neuropil. In contrast, sections from 5 of the 21 stroke subjects exhibited cellular patterns of IgG immunostaining that appeared different from subject to subject. This may be indicative of autoantibodies binding to a diverse array of CNS antigens. Figure $9 C$ depicts 1 of 2 control subjects whose brain exhibited light immunostaining for IgG and also depicts 1 of the 5 subjects with well-defined anti-IgG immunostaining in the neuropil that was scored as "IgG ${ }^{+}$." There was no significant difference between B-cell densities in subjects without IgG in the neuropil and controls; however, subjects with IgG immunoreactivity in the neuropil exhibited higher B-cell densities than controls (Fig. 9D).

\section{Discussion}

Our findings in mice demonstrate that B-lymphocyte-mediated inflammation in a stroke lesion can directly impact cognition. To our knowledge, this is the first time that chronic inflammatory responses in the infarct core in general, or B-lymphocyte re- 
A

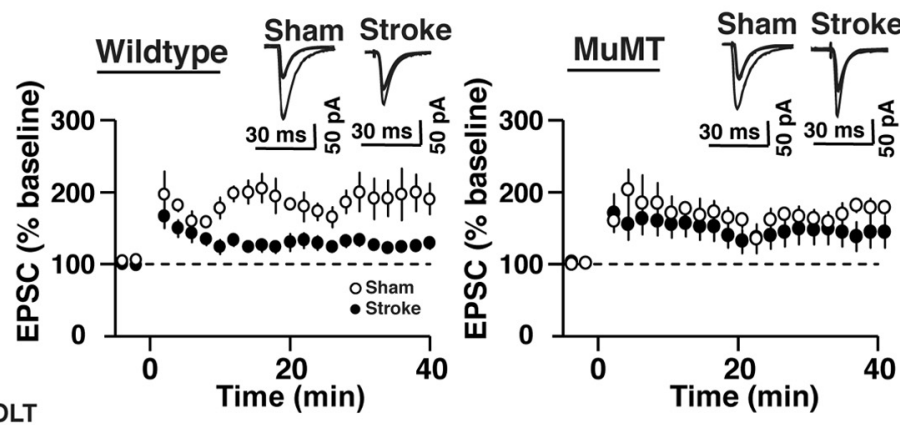

Sham Stroke B

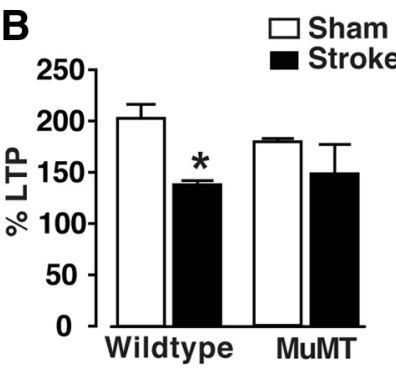

C OLT
in
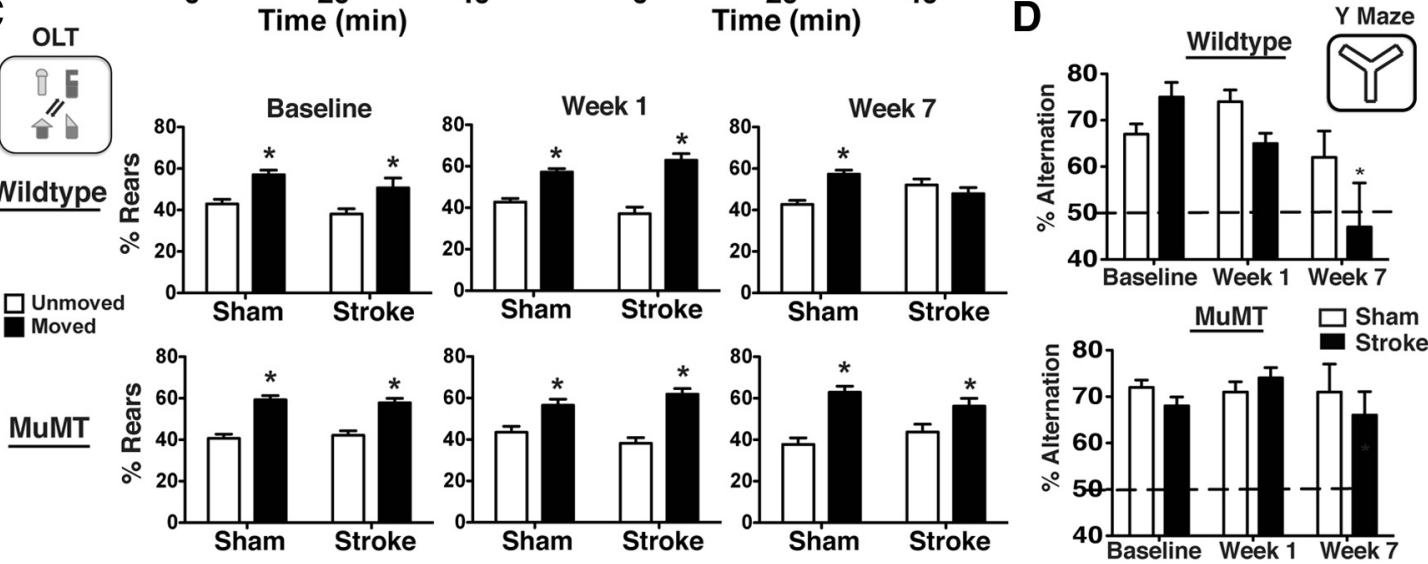

Figure 6. B-cell-deficient muMT mice do not develop either LTP or cognitive deficits in the weeks after stroke. $A, B$, Whole-cell EPSCs were recorded from CA1 pyramidal neurons in acute hippocampal slices prepared from WT and muMT mice that had undergone DH stroke or sham surgery 12 weeks earlier $(n=6-9$ per group). The time course $(\boldsymbol{A})$ and magnitude $(\boldsymbol{B})$ of LTP demonstrated that muMT mice that had undergone DH stroke did not develop an LTP impairment 12 weeks following stroke. ${ }^{*} p<0.05$, compared with WT sham control. There was no difference between sham groups $(p=0.85)$. LTP plot represents $0-40 \mathrm{~min}$ after LTP. Values in the bar graph were taken at $35 \mathrm{~min}$ after LTP. C, muMT mice also did not develop a cognitive deficit on the 0 LT test 7 weeks after DH stroke ( $n=10$ per group). ${ }^{*} p<0.05$, compared with unmoved objects. $\boldsymbol{D}$, WT, but not $m u M T$, mice developed a cognitive deficit on the $Y$ maze 7 weeks after DH stroke $(n=$ 10 per group). ${ }^{*} p<0.05$, compared with sham.

A

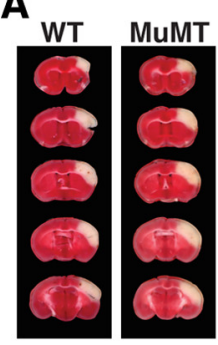

D
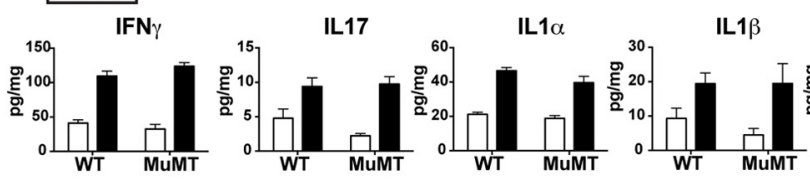

B
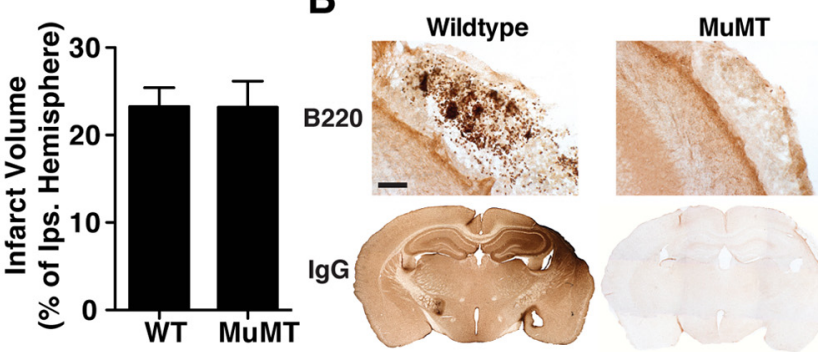

C
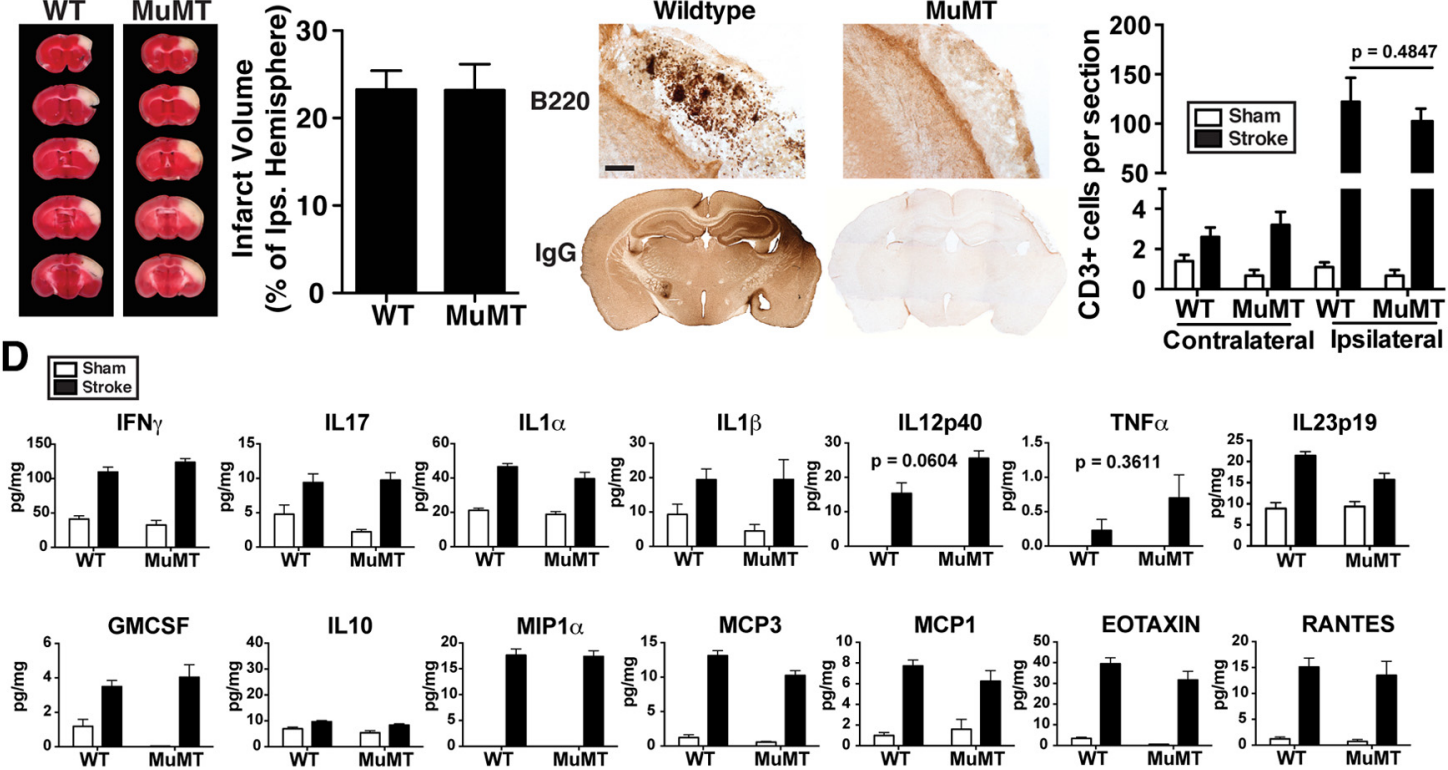

Figure 7. Lesion size and the T-lymphocyte response to stroke are equivalent in WT and muMT mice. $A, B$-cell-deficient muMT mice and wild-type (WT) $(57 B L / 6$ J mice had equivalent infarct volumes $72 \mathrm{~h}$ after DH stroke ( $n=5$ per group). $\boldsymbol{B}$, muMT mice did not have B cell (B22 ${ }^{+}$) or lgG immunostaining in the lesion 7 weeks after DH stroke $(n=10)$. Scale bar, 125 $\mu \mathrm{m}$. C, The number of T cells in the brain was equivalent in WT and muMT mice 7 weeks after stroke. $\boldsymbol{D}$, Levels of proinflammatory cytokines and chemokines in the lesion were similarly elevated in both WT and muMT mice compared with corresponding cortical tissue from sham mice 7 weeks after DH stroke (sham, $n=4$ per group; DH stroke, $n=7$ per group). There was no difference between WT and muMT mice by two-way ANOVA. The $p$ value before correcting for multiple comparisons is shown for IL12p40 and TNF $\alpha$, which were not different statistically. 
A Isotype Control Ab
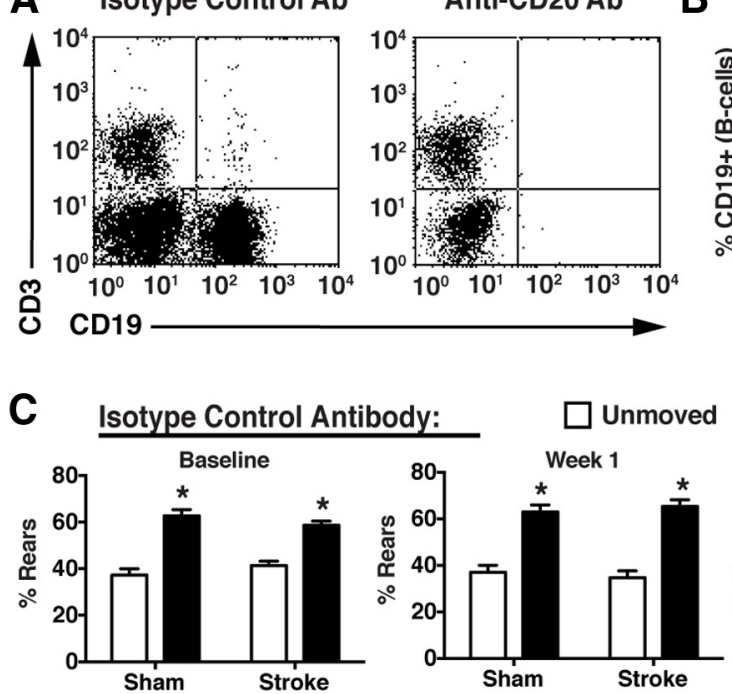

Anti-CD20 Antibody:
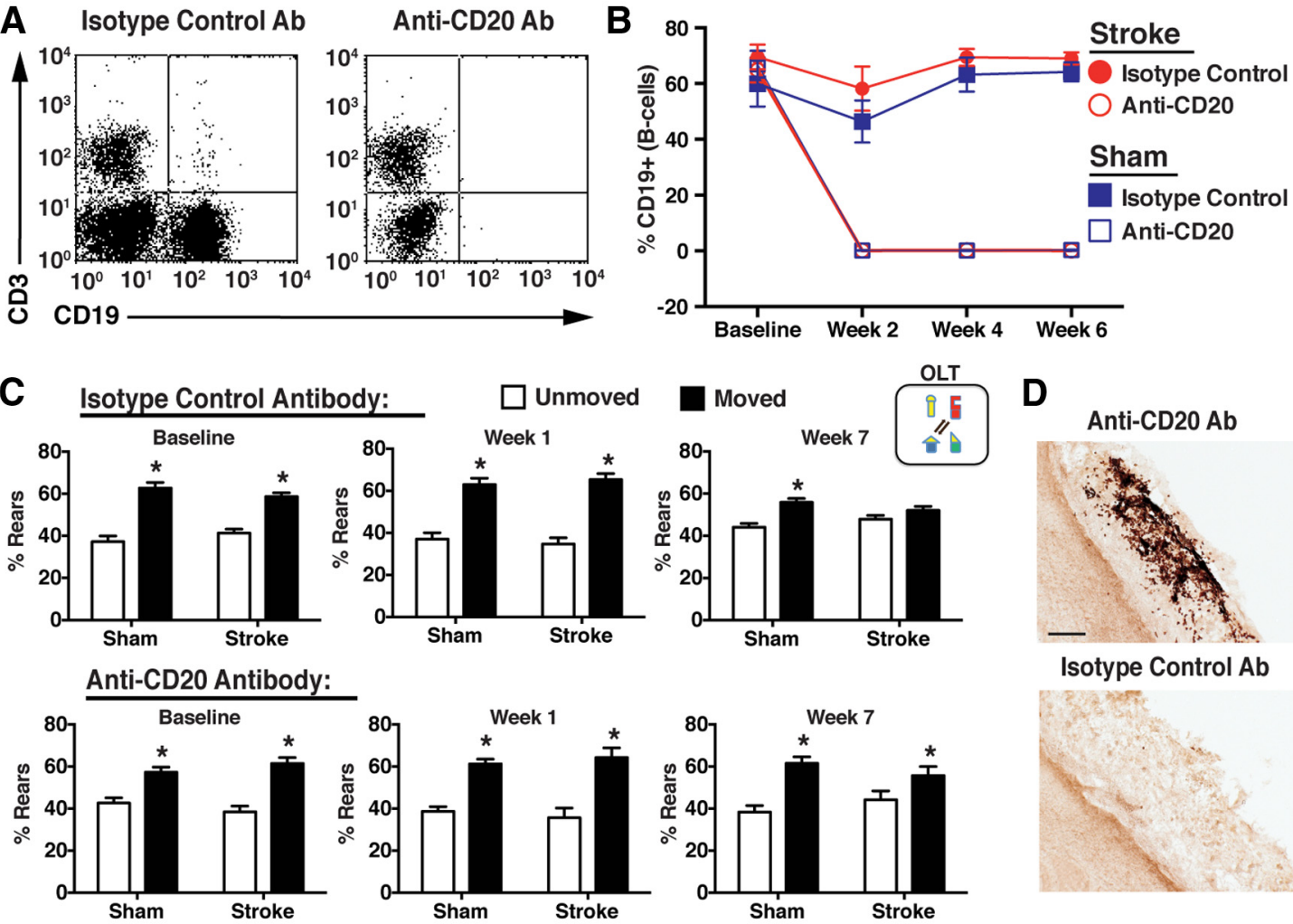

D

Anti-CD20 Ab

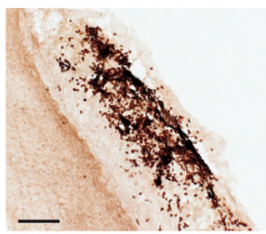

Isotype Control Ab

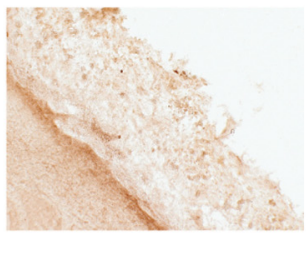

E

Isotype Control Ab
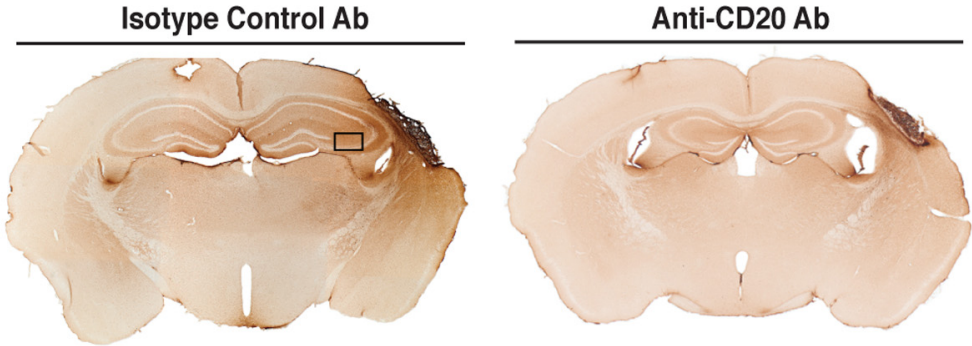

F Normalized Mean Gray Value

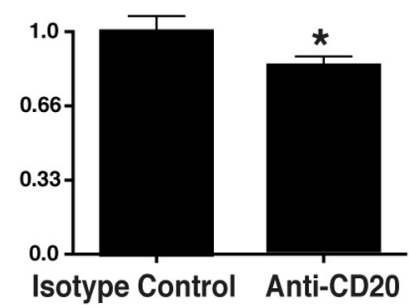

Figure 8. B-cell depletion with an anti-CD20 antibody beginning $5 \mathrm{~d}$ after stroke ameliorates the development of delayed cognitive deficits. $A$, Representative scatter plot showing complete B-cell ablation $7 \mathrm{~d}$ following injection with anti-CD20 antibody. CD3, T-cell marker; CD19, B-cell marker. B, Flow cytometry showed that B-cell ablation was sustained throughout the experiment in the mice treated with the anti-CD20 antibody. C, Isotype control-treated, but not anti-CD20 antibody-treated, mice developed a cognitive deficit on the 0LT test. Data are from 7 weeks after DH stroke ( $n=10$ per group). ${ }^{*} p<0.05$, compared with unmoved objects. $\boldsymbol{D}$, Anti-CD20 antibody-treated mice did not have B-cell (B220 ${ }^{+}$) infiltration in the lesion 7 weeks after stroke. Scale bar, $125 \mu \mathrm{m}$. E, Anti-CD20 antibody-treated mice exhibited less lgG infiltration in the lesion and hippocampus 7 weeks after stroke. Black box represents region where grayscale was quantified in IgG-stained sections, demonstrating less immunostaining in anti-CD20-treated mice $(\boldsymbol{F}) . n=8-10$ per group. ${ }^{*} p<0.05$.

sponses in particular, have been shown to cause delayed-onset cognitive impairment after stroke.

We found that by 4-7 weeks after stroke there are both B- and T-lymphocytes present in the stroke core in four different stroke models: $\mathrm{DH}$, transient proximal MCAO, and photothrombotic stroke in wild-type C57BL/6J mice, and DMCAO stroke in wildtype BALB/CJ mice. We also demonstrated that mice develop delayed cognitive deficits following DH stroke in C57BL/6J mice and DMCAO in BALB/CJ mice. We used these mouse models because they do not cause an immediate cognitive deficit, and different stroke models in each strain because they each have different vulnerabilities to DMCAO.

In BALB/CJ mice, DMCAO generates a lesion that incorporates the frontal and parietal cortex and is adjacent to, but does not incorporate, the hippocampus. In C57BL/6J mice, DMCAO only generates a small lesion in the frontal cortex, and hypoxia is required to enlarge the lesion to the parietal cortex and place it in closer proximity to the hippocampus (Doyle et al., 2012). In both models, an immediate short-term memory deficit is lacking.
However, mice develop a deficit within 7 weeks of a $\mathrm{DH}$ or DMCAO stroke. C57BL/6J mice that underwent DMCAO (without hypoxia) did not develop a short-term memory deficit (data not shown). Enlargement of the lesion in C57BL/6J mice might be important for the emergence of the delayed cognitive deficit because the larger lesion is in cortex adjacent to the hippocampus.

The delayed appearance of cognitive deficits in our mouse models mimics what is observed in human studies where stroke survivors without dementia have an at least twofold risk of developing dementia in the decade following their stroke (Desmond et al., 2002; Ivan et al., 2004). The chronic inflammation we observe in mice is also consistent with the B-lymphocytes and human IgG we observed in the brains of people who died with stroke and dementia. Consistent with our findings here, Mena et al. (2004) and Mărgăritescu et al. (2009) reported persistent immune cell infiltration, sometimes decades after stroke, in $\sim 40 \%$ of human cerebral infarcts stained with hematoxylin and eosin.

Within the stroke lesion in mice, B-lymphocytes aggregated into clusters and were surrounded by macrophages and 
T-lymphocytes, and so may represent tertiary lymphoid structures. Similar aggregates have been found in sites of chronic inflammation in other diseases, where they correlate with increased severity of disease (Ankeny et al., 2006, 2009; Carragher et al., 2008; Ankeny and Popovich, 2010; Neyt et al., 2012). In addition to IgG, we found evidence of IgA production in mice, similar to that reported in human multiple sclerosis (Bernheimer et al., 1983; Zhang et al., 2005).

Chronic inflammation is unlikely to be due to bacterial brain infection because it occurs in photothrombotic stroke, which does not require the skull to be opened. There was also no evidence of bacteria on hematoxylin and eosin stains of brain sections from C57BL/6J mice killed on days 1,3 , and 7 or 1 and 3 months after $\mathrm{DH}$ stroke (data not shown).

B-lymphocyte aggregates have been found in mice in the injured spinal cord where they produce antibodies and impair recovery (Ankeny and Popovich, 2010). Here, we showed that a substantial amount of antibody is present in areas of the brain adjacent to B-cell clusters that form in the stroke core. We speculate that plasma cells in the stroke core might be producing autoreactive antibodies or antibodies that activate $\mathrm{Fc}$ receptors and complement, and that those antibodies diffuse into the surrounding tissue and cause neurological dysfunction. In support of this hypothesis, we observed a deficit in hippocampal LTP in a time frame similar to that of antibody accumulation. The development of a deficit in LTP could explain why mice acquired a short-term memory deficit in the weeks after stroke.

Ankeny et al. (2006, 2009) have shown that B-lymphocyte-deficient mice have improved locomotor function and reduced spinal pathology after spinal cord injury compared with wild-type mice. Therefore, we tested whether B-lymphocyte-deficient muMT mice were protected from delayed cognitive deficits after stroke. We found that the genetic ablation of mature B-lymphocytes prevented the emergence of delayed cognitive deficits.

To investigate the translational potential of ablating B-lymphocytes after stroke, we tested whether ablating B cells using intravenous administration of an anti-CD20 antibody could also prevent the emergence of delayed cognitive deficits. We began treatment $5 \mathrm{~d}$ after stroke, and antibody treatment successfully ablated B cells in the circulation, prevented their recruitment to the brain, and prevented the appearance of delayed cognitive deficits. A chimeric version of the monoclonal anti-CD20 antibody we used here, rituximab, is FDA-approved as a B-cell-depleting drug for rheumatoid arthritis, CD20 ${ }^{+}$non-Hodgkin's lymphoma, chronic lymphocytic leukemia, granulomatosis with polyangiitis, and microscopic poly-

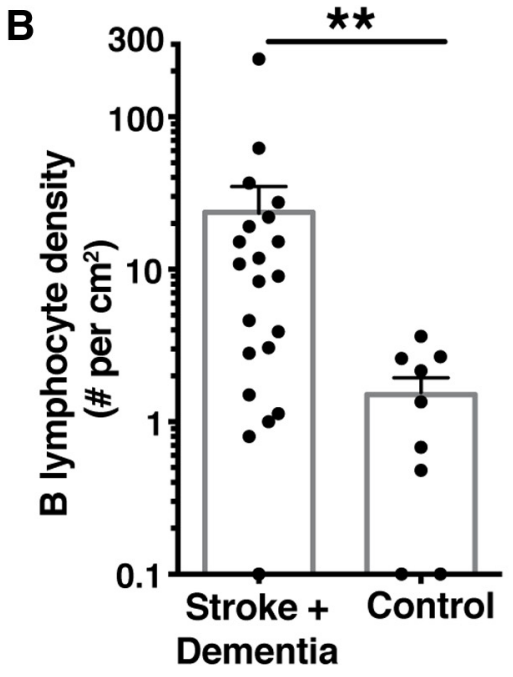

D

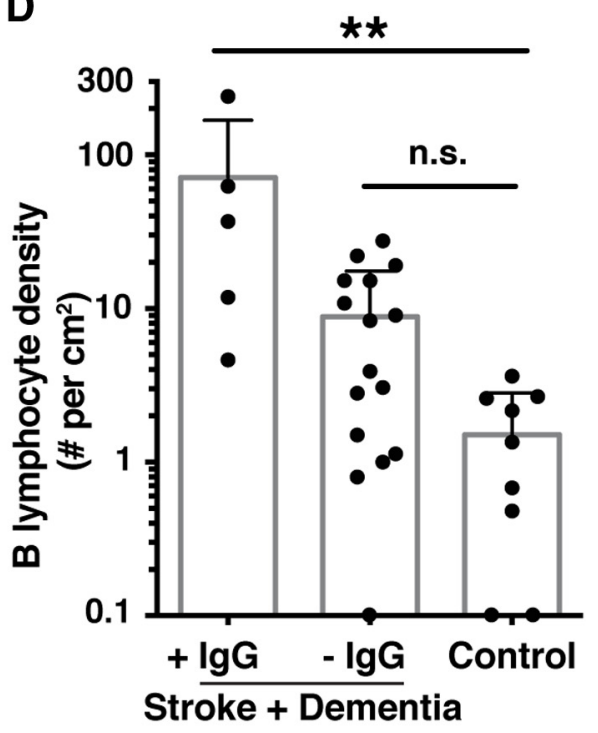

Figure 9. Evidence of a $B$-cell response in the brain after stroke in humans with concurrent dementia. $\boldsymbol{A}, \mathrm{CD} 20$ immunostaining from an ischemic infarct that had a density of 240 B-lymphocytes $/ \mathrm{cm}^{2}$. Scale bar, $25 \mu \mathrm{m}$. B, Quantification of B-cell infiltration in (Kruskal-Wallis with Dunn's multiple-comparison post hoc test). n.s., Not significant. More detailed information on B-cell densities, IgG immunoreactivity, and associated clinical information is provided in Table 2.

angiitis (Grillo-López et al., 1999, 2002; Montserrat, 2003; Perosa et al., 2010; Scher, 2012). Intrathecal administration of rituximab, as used in CNS lymphoma and multiple sclerosis (Rubenstein et al., 2003; Studer et al., 2014), might also be effective. It was also recently shown that ${ }^{124}$ I-rituximab could be used to image CD20-positive B-lymphocytes at sites of inflammation in patients with rheumatoid arthritis using PET imaging (Tran et al., 2011). Thus, trace amounts of rituximab could be used to identify the presence of B-lymphocytes in the brains of stroke patients and potentially identify those that might benefit from rituximab treatment after stroke.

Ren et al. (2011) reported that regulatory B cells limit CNS inflammation and are beneficial for outcomes in the first few days after stroke, although others reported that B cells are of minor relevance during the acute phase of stroke injury (Kleinschnitz et al., 2010). Regardless of these findings in the acute phase of 
Table 2. Clinical and immunohistological characterization of human subjects and specimens ${ }^{a}$

\begin{tabular}{|c|c|c|c|c|c|c|c|c|}
\hline Case ID & Tissue source & Sex & Age (yr) & Total no. of infarcts & Total infarct volume $\left(\mathrm{mm}^{3}\right)$ & MMSE score & B cells per $\mathrm{cm}^{2}$ area & $\operatorname{lgG}$ immunoreactivity? \\
\hline \multicolumn{9}{|l|}{ Subjects } \\
\hline 91018909 & RMAP & Male & 91 & 4 & 48 & 24 & 1.0 & No \\
\hline 70726480 & RMAP & Female & 79 & 2 & 3300 & 12 & 3.9 & No \\
\hline 93787649 & RMAP & Male & 86 & 7 & 1120 & 27 & 8.3 & No \\
\hline 42680008 & RMAP & Female & 87 & 3 & 945,000 & 9 & 9.0 & No \\
\hline 50300408 & RMAP & Female & 87 & 2 & 18,000 & 18 & 15.2 & No \\
\hline 11453772 & RROS & Male & 80 & 3 & 135 & 19 & 0.0 & No \\
\hline 20934339 & RROS & Female & 91 & 2 & 2000 & 18 & 0.8 & No \\
\hline 10345561 & RROS & Male & 92 & 1 & 50 & 13 & 1.1 & No \\
\hline 20439591 & RROS & Female & 95 & 1 & 5625 & 19 & 1.5 & No \\
\hline 20453625 & RROS & Female & 92 & 5 & 5700 & 1 & 2.8 & No \\
\hline 10447620 & RROS & Male & 84 & 3 & 500 & 9 & 3.1 & No \\
\hline 42874904 & RROS & Female & 96 & 1 & 600 & 19 & 4.6 & Yes \\
\hline 11413170 & RROS & Male & 70 & 1 & 84,000 & 5 & 10.8 & No \\
\hline 20179164 & RROS & Female & 84 & 2 & 250 & 8 & 11.8 & Yes \\
\hline 20275399 & RROS & Female & 88 & 4 & 512 & 22 & 15.2 & No \\
\hline 10292311 & RROS & Male & 90 & 1 & 27 & 26 & 19.1 & No \\
\hline 21402304 & RROS & Female & 95 & 2 & 60 & 24 & 22.0 & No \\
\hline 11275158 & RROS & Male & 86 & 1 & 150 & 1 & 27.5 & No \\
\hline 15495024 & RROS & Male & 87 & 2 & 3570 & 23 & 36.8 & Yes \\
\hline 20951100 & RROS & Female & 90 & 1 & 40,000 & 9 & 62.4 & Yes \\
\hline 20630946 & RROS & Female & 104 & 1 & 630 & 25 & 239.8 & Yes \\
\hline \multicolumn{9}{|l|}{ Controls } \\
\hline 11331231 & RROS & Male & 81 & 0 & NA & 27 & 0.7 & No \\
\hline 11335695 & RROS & Male & 84 & 0 & NA & 28 & 0.5 & No \\
\hline 11399321 & RROS & Male & 87 & 0 & NA & 25 & 2.6 & No \\
\hline 15138884 & RROS & Male & 86 & 0 & NA & 30 & 1.4 & No \\
\hline 15196262 & RROS & Male & 81 & 0 & NA & 28 & 3.6 & No \\
\hline 20207013 & RROS & Female & 96 & 0 & NA & 30 & 2.2 & No \\
\hline 20261613 & RROS & Female & 91 & 0 & NA & 30 & 0 & No \\
\hline 20993308 & RROS & Female & 83 & 0 & NA & 26 & 2.7 & No \\
\hline 50301413 & RMAP & Female & 94 & 0 & NA & 25 & 0 & No \\
\hline
\end{tabular}

${ }^{a} \mathrm{lgG}$ immunoreactivity was scored as "Yes" if there was a clear pattern of cellular staining in the neuropil. Faint cellular staining (as shown in Figure 9B), faint positivity of white matter, and perivascular and meningeal staining were all seen in controls as well as stroke + dementia subjects and so were scored as "No." RROS, Rush Religious Orders Study; RMAP, Rush Memory and Aging Project; NA, not applicable.

stroke, the data we present here demonstrate that B cells cause later neurologic impairment weeks after stroke. This may be similar to the reciprocal role of B cells in experimental EAE. In EAE, IL10-expressing regulatory B cells are beneficial early in disease, but other B cells are detrimental later (Matsushita et al., 2008). We postulate that, early in stroke, IL10-producing regulatory B cells may be beneficial, whereas later during recovery from stroke, autoantibody-producing plasma cells become detrimental.

We also postulate that the mechanism by which B-lymphocytes contribute to cognitive dysfunction after stroke is via the production of brain-reactive antibodies. Brain-reactive antibodies are linked to pathogenesis in many other neurological disorders, such as spinal cord injury, systemic lupus erythematosus, and neuromyelitis optica, and can recognize and interfere with many molecules important for key brain functions, such as neurotransmission, blood-brain barrier function, and protein translation (for review, see Diamond et al., 2009). In addition, autoantibodies can ligate $\mathrm{Fc}$ receptors, initiate cytokine signaling pathways, and activate complement. It is not yet clearly established by which of these mechanisms brain-reactive antibodies contribute to symptoms of disease in the CNS, but it is likely that a different combination of mechanisms is important in different diseases and individuals.

The mechanism by which B-lymphocytes contribute to cognitive dysfunction is likely to involve T-lymphocytes. We found abundant T-lymphocytes and MHCII expression in the lesion and in an area of Wallerian degeneration 7 weeks following stroke, and the presence of these cells, in conjunction with pro- inflammatory cytokines is suggestive that stroke elicits a prolonged T-lymphocyte response within the brain. Additionally, we found evidence of isotype switching, which is typically T-celldependent (Bishop and Hostager, 2001; Cerutti, 2008), with increased IgA present in the brain 7 weeks following stroke in both mouse models. However, muMT mice did not develop delayed cognitive deficits after stroke yet had equivalent $\mathrm{T}$-cell infiltration and cytokine concentrations in the brain as wild-type C57BL/6J mice. These $\mathrm{T}$-cell responses alone were thus not sufficient to cause electrophysiologic or cognitive deficits in the absence of B-lymphocytes.

There are limitations to using rodents to model cognitive dysfunction in humans. For instance, stroke patients often have multiple comorbidities, such as age, periventricular white matter disease, other types of vascular dementia, and Alzheimer's disease (Barba et al., 2000; Ivan et al., 2004; Leys et al., 2005; Troncoso et al., 2008; Savva and Stephan, 2010; Gorelick et al., 2011; Iadecola, 2013). Indeed, in human populations, classic neuropathological findings of disease, including strokes and other vascular pathology, explain only $41 \%$ of the risk of overall cognitive decline (Boyle et al., 2013). However, we present evidence here from autopsy tissue that implicates B-lymphocyte infiltration as a novel factor that potentially confers an increased risk of cognitive decline to humans with stroke and may contribute to a more comprehensive understanding of cognitive impairment. It will now be important to define both the duration and characteristics of adaptive immune responses in people who have suffered a 
stroke and determine whether they correlate with the development of poststroke dementia in some patients.

\section{References}

Ankeny DP, Popovich PG (2010) B cells and autoantibodies: complex roles in CNS injury. Trends Immunol 31:332-338. CrossRef Medline

Ankeny DP, Lucin KM, Sanders VM, McGaughy VM, Popovich PG (2006) Spinal cord injury triggers systemic autoimmunity: evidence for chronic B lymphocyte activation and lupus-like autoantibody synthesis. J Neurochem 99:1073-1087. CrossRef Medline

Ankeny DP, Guan Z, Popovich PG (2009) B cells produce pathogenic antibodies and impair recovery after spinal cord injury in mice. J Clin Invest 119:2990-2999. CrossRef Medline

Arac A, Brownell SE, Rothbard JB, Chen C, Ko RM, Pereira MP, Albers GW, Steinman L, Steinberg GK (2011) Systemic augmentation of alphaBcrystallin provides therapeutic benefit twelve hours post-stroke onset via immune modulation. Proc Natl Acad Sci U S A 108:13287-13292. CrossRef Medline

Barba R, Martínez-Espinosa S, Rodríguez-García E, Pondal M, Vivancos J, Del Ser T (2000) Poststroke dementia: clinical features and risk factors. Stroke 31:1494-1501. CrossRef Medline

Béjot Y, Aboa-Eboulé C, Durier J, Rouaud O, Jacquin A, Ponavoy E, Richard D, Moreau T, Giroud M (2011) Prevalence of early dementia after first-ever stroke: a 24-year population-based study. Stroke 42:607-612. CrossRef Medline

Bennett DA, Schneider JA, Arvanitakis Z, Wilson RS (2012a) Overview and findings from the religious orders study. Curr Alzheimer Res 9:628-645. CrossRef Medline

Bennett DA, Schneider JA, Buchman AS, Barnes LL, Boyle PA, Wilson RS (2012b) Overview and findings from the Rush Memory and Aging Project. Curr Alzheimer Res 9:646-663. CrossRef Medline

Bernheimer H, Budka H, Müller P (1983) Brain tissue immunoglobulins in adrenoleukodystrophy: a comparison with multiple sclerosis and systemic lupus erythematosus. Acta Neuropathol 59:95-102. CrossRef Medline

Bishop GA, Hostager BS (2001) B lymphocyte activation by contactmediated interactions with T lymphocytes. Curr Opin Immunol 13:278285. CrossRef Medline

Boyle PA, Wilson RS, Yu L, Barr AM, Honer WG, Schneider JA, Bennett DA (2013) Much of late life cognitive decline is not due to common neurodegenerative pathologies. Ann Neurol 74:478-489. CrossRef Medline

Carragher DM, Rangel-Moreno J, Randall TD (2008) Ectopic lymphoid tissues and local immunity. Semin Immunol 20:26-42. CrossRef Medline

Cerutti A (2008) The regulation of IgA class switching. Nat Rev Immunol 8:421-434. CrossRef Medline

Desmond DW, Moroney JT, Sano M, Stern Y (2002) Incidence of dementia after ischemic stroke: results of a longitudinal study. Stroke 33:22542260. CrossRef Medline

Diamond B, Huerta PT, Mina-Osorio P, Kowal C, Volpe BT (2009) Losing your nerves? Maybe it's the antibodies. Nat Rev Immunol 9:449-456. CrossRef Medline

Doyle KP, Cekanaviciute E, Mamer LE, Buckwalter MS (2010) TGFbeta signaling in the brain increases with aging and signals to astrocytes and innate immune cells in the weeks after stroke. J Neuroinflammation 7:62. CrossRef Medline

Doyle KP, Fathali N, Siddiqui MR, Buckwalter MS (2012) Distal hypoxic stroke: a new mouse model of stroke with high throughput, low variability and a quantifiable functional deficit. J Neurosci Methods 30:31-40. CrossRef Medline

Galea I, Bechmann I, Perry VH (2007) What is immune privilege (not)? Trends Immunol 28:12-18. CrossRef Medline

Gorelick PB, Scuteri A, Black SE, Decarli C, Greenberg SM, Iadecola C, Launer LJ, Laurent S, Lopez OL, Nyenhuis D, Petersen RC, Schneider JA, Tzourio C, Arnett DK, Bennett DA, Chui HC, Higashida RT, Lindquist R, Nilsson PM, Roman GC, et al. (2011) Vascular contributions to cognitive impairment and dementia: a statement for healthcare professionals from the American Heart Association/American Stroke Association. Stroke 42:2672-2713. CrossRef Medline

Grillo-López AJ, White CA, Varns C, Shen D, Wei A, McClure A, Dallaire BK (1999) Overview of the clinical development of rituximab: first monoclonal antibody approved for the treatment of lymphoma. Semin Oncol 26[Suppl 14]:66-73. Medline

Grillo-López AJ, Hedrick E, Rashford M, Benyunes M (2002) Rituximab: ongoing and future clinical development. Semin Oncol 29[1 Suppl 2]: 105-112. CrossRef;/Border http://dx.doi.org/10.1053/sonc.2002.30145 Medline

Hattori K, Lee H, Hurn PD, Crain BJ, Traystman RJ, DeVries AC (2000) Cognitive deficits after focal cerebral ischemia in mice. Stroke 31:1939_ 1944. CrossRef Medline

Iadecola C (2013) The pathobiology of vascular dementia. Neuron 80:844866. CrossRef Medline

Ivan CS, Seshadri S, Beiser A, Au R, Kase CS, Kelly-Hayes M, Wolf PA (2004) Dementia after stroke: the Framingham Study. Stroke 35:1264-1268. CrossRef Medline

Kleinschnitz C, Schwab N, Kraft P, Hagedorn I, Dreykluft A, Schwarz T, Austinat M, Nieswandt B, Wiendl H, Stoll G (2010) Early detrimental $\mathrm{T}$-cell effects in experimental cerebral ischemia are neither related to adaptive immunity nor thrombus formation. Blood 115:3835-3842. CrossRef Medline

Kowal C, DeGiorgio LA, Nakaoka T, Hetherington H, Huerta PT, Diamond B, Volpe BT (2004) Cognition and immunity: antibody impairs memory. Immunity 21:179-188. CrossRef Medline

Kozakiewicz L, Chen Y, Xu J, Wang Y, Dunussi-Joannopoulos K, Ou Q, Flynn JL, Porcelli SA, Jacobs WR Jr, Chan J (2013) B cells regulate neutrophilia during Mycobacterium tuberculosis infection and BCG vaccination by modulating the interleukin-17 response. PLoS Pathogens 9:e1003472. CrossRef Medline

Leys D, Hénon H, Mackowiak-Cordoliani MA, Pasquier F (2005) Poststroke dementia. Lancet Neurol 4:752-759. CrossRef Medline

Lynch MA (2004) Long-term potentiation and memory. Physiol Rev 84:87136. CrossRef Medline

Mărgăritescu O, Mogoanta L, Pirici I, Pirici D, Cernea D, Mărgăritescu C (2009) Histopathological changes in acute ischemic stroke. Rom J Morphol Embryol 50:327-339. Medline

Matsushita T, Yanaba K, Bouaziz JD, Fujimoto M, Tedder TF (2008) Regulatory B cells inhibit EAE initiation in mice while other B cells promote disease progression. J Clin Invest 118:3420-3430. CrossRef Medline

McGeorge AJ, Faull RL (1989) The organization of the projection from the cerebral cortex to the striatum in the rat. Neuroscience 29:503-537. CrossRef Medline

Mena H, Cadavid D, Rushing EJ (2004) Human cerebral infarct: a proposed histopathologic classification based on 137 cases. Acta Neuropathol 108: 524-530. CrossRef Medline

Montserrat E (2003) Rituximab in chronic lymphocytic leukemia. Semin Oncol 30:34-39. CrossRef Medline

Neyt K, Perros F, GeurtsvanKessel CH, Hammad H, Lambrecht BN (2012) Tertiary lymphoid organs in infection and autoimmunity. Trends Immunol 33:297-305. CrossRef Medline

Perosa F, Prete M, Racanelli V, Dammacco F (2010) CD20-depleting therapy in autoimmune diseases: from basic research to the clinic. J Intern Med 267:260-277. CrossRef Medline

Prüss H, Iggena D, Baldinger T, Prinz V, Meisel A, Endres M, Dirnagl U, Schwab JM (2012) Evidence of intrathecal immunoglobulin synthesis in stroke: a cohort study. Arch Neurol 69:714-717. CrossRef Medline

Ren X, Akiyoshi K, Dziennis S, Vandenbark AA, Herson PS, Hurn PD, Offner H (2011) Regulatory B cells limit CNS inflammation and neurologic deficits in murine experimental stroke. J Neurosci 31:8556-8563. CrossRef Medline

Roström B, Link B (1981) Oligoclonal immunoglobulins in cerebrospinal fluid in acute cerebrovascular disease. Neurology 31:590-596. CrossRef Medline

Rubenstein JL, Combs D, Rosenberg J, Levy A, McDermott M, Damon L, Ignoffo R, Aldape K, Shen A, Lee D, Grillo-López A, Shuman MA (2003) Rituximab therapy for CNS lymphomas: targeting the leptomeningeal compartment. Blood 101:466-468. CrossRef Medline

Savva GM, Stephan BC (2010) Epidemiological studies of the effect of stroke on incident dementia: a systematic review. Stroke 41:e41-e46. CrossRef Medline

Scher JU (2012) B-cell therapies for rheumatoid arthritis. Bull NYU Hosp Jt Dis 70:200-203. Medline

Studer V, Rossi S, Motta C, Buttari F, Centonze D (2014) Peripheral B cell depletion and central proinflammatory cytokine reduction following repeated intrathecal administration of rituximab in progressive multiple sclerosis. J Neuroimmunol 276:229-231. CrossRef Medline

Tran L, Huitema AD, van Rijswijk MH, Dinant HJ, Baars JW, Beijnen JH, Vogel WV (2011) CD20 antigen imaging with (1)(2)(4)I-rituximab 
PET/CT in patients with rheumatoid arthritis. Hum Antibodies 20:2935. CrossRef Medline

Troncoso JC, Zonderman AB, Resnick SM, Crain B, Pletnikova O, O’Brien RJ (2008) Effect of infarcts on dementia in the Baltimore Longitudinal Study of Aging. Ann Neurol 64:168-176. CrossRef Medline

Truong DT, Venna VR, McCullough LD, Fitch RH (2012) Deficits in auditory, cognitive, and motor processing following reversible middle cerebral artery occlusion in mice. Exp Neurol 238:114-121. CrossRef Medline

Tsementzis SA, Chao SW, Hitchcock ER, Gill JS, Beevers DG (1986) Oligoclonal immunoglobulin $\mathrm{G}$ in acute subarachnoid hemorrhage and stroke. Neurology 36:395-397. CrossRef Medline

Varallyay CG, Nesbit E, Fu R, Gahramanov S, Moloney B, Earl E, Muldoon LL, Li X, Rooney WD, Neuwelt EA (2013) High-resolution steady-state cerebral blood volume maps in patients with central nervous system neoplasms using ferumoxytol, a superparamagnetic iron oxide nanoparticle. J Cereb Blood Flow Metab 33:780-786. CrossRef Medline

Vargas ME, Barres BA (2007) Why is Wallerian degeneration in the CNS so slow? Annu Rev Neurosci 30:153-179. CrossRef Medline

Wykes M, MacPherson G (2000) Dendritic cell-B-cell interaction: dendritic cells provide B cells with CD40-independent proliferation signals and CD40-dependent survival signals. Immunology 100:1-3. CrossRef Medline

Zhang Y, Da RR, Hilgenberg LG, Tourtellotte WW, Sobel RA, Smith MA, Olek M, Nagra R, Sudhir G, van den Noort S, Qin Y (2005) Clonal expansion of IgA-positive plasma cells and axon-reactive antibodies in MS lesions. J Neuroimmunol 167:120-130. CrossRef Medline 